\title{
Country Value Premiums and Financial Crises
}

\author{
Adam Zaremba
}

Poznań University of Economics, Poland

\begin{abstract}
The paper concentrates on the value premium across countries and contributes to the investment and asset pricing literature in three ways. First, I provide fresh evidence that the high-value countries perform significantly better than the low-value countries. Additionally, this phenomenon is indifferent to the choice of the computational currency, representative index or value indicator. Second, I demonstrate that the value effect can be successfully amplified by combining with country-level size and momentum effects. Third, I show that returns to the high-value countries deteriorate in financial crisis conditions, because the country-level value premium is negatively correlated with the credit spreads, TED spread and expected volatility. I examine data from 66 markets between years 2000 and 2013 .
\end{abstract}

Keywords: inter-country variation in stock returns; value premium; financial crisis.

(C) 2014 Published by SSBFNET

\section{Introduction}

The value effect is one the most extensively documented anomalies in the stock market (Fama and French 2012, Asness, Moskowitz, and Pedersen 2013). It implies that stocks with high ratio of fundamentals to price perform better in the long term then the stocks with low ratio. Although the value premium is well acknowledged, the reason it exist is still to some extend a mystery. There are two basic explanations: the neoclassical story, which attributes premium to non-market risks (Fama and French 1993, 1995, 1996, Davis et al. 2000, Lettau and Ludvigson 2001, Zhang 2005, Campbell et al. 2009) and the behavioral story of stock mispricing (De Bondt and Thaler 1985, Lakonishok et al. 1994, Daniel and Titman 1997, Daniel et al. 1998, Barberis and Shleifer 2003).

The value effect is usually analyzed across single stocks and used to explain the cross-sectional variation in their rates of return. However, there are also some parallels on the macro level. There is some evidence, that "cheaper" countries perform better than "expensive" ones. This observation may have interesting implications for the debate on sources of the value premium. It would suggest that either whole markets are exposed to greater risks, or that whole markets are fundamentally undervalued. Additionally, a question emerges how the value and growth markets perform, when the perception of global risk factors (credit, liquidity etc.) increases and decreases. The both theories may have different 
implications for the time-variation of value premium along the business cycle and suggest that it could be either procyclical or countercyclical.

In this paper I attempt to contribute to the asset pricing and investment theory in three ways. First, I extensively document the value premium in inter-market returns. I based my computations on a broad data sample from 66 developed, emerging and frontier markets in years 2000-2013. Additionally, I show that the premium is statistically significant and robust to the choice of value ratio and generally works for either earnings yield, cash flow yield, sales to price ratio or book to market value ratio. What is more, I demonstrate, the premium size is indifferent to the choice of functional currency or type of representative market index. Country-level value investing works in US dollars, euros and Japanese yens with both unified MSCI indices or local stock exchanges' indices.

Second, I present the interactions between inter-country value premium and inter country momentum and size factors. It turns out that the correlation between macro-level momentum, value and size premiums is relatively low and it was historically possible to form global portfolios based on combinations of value and other pricing factors, which delivered significant abnormal returns.

Third, I examine how the inter-country value premium performs during in the crisis circumstances and during amplified financial stress. In this case I contribute to the discussion on sources of the value premium. Naturally, what actually are the crisis condition, is a highly subjective thing. Therefore, I use various factors reflecting the perception of risk, which are derived from market prices. I investigate the relationship between global macro-value premium with credit spreads, interbank liquidity and expected market volatility. Additionally, I analyze the relation with expected economic conditions. The results of the empirical analysis indicate, that there is a significant negative correlation between changes in perceived risk and returns to value factors. The more "crisis-like" the market becomes, the worse the value premium performs. This observations seems to support the risk story as an explanation for the value premium.

The paper is composed of three parts. First, I provide the theoretical basis for the research. Second, I describe the data sources and research methods employed. Finally, I present the results of the empirical analysis. The paper ends with conclusions.

\section{Literature Review}

The value effect dates back to Graham and Dodd (1934) is probably one of the oldest anomalies documented in the stock market. It is basically a tendency of stocks with a high relation of fundamental variables to price (value stocks) to outperform in the long term stocks with a low relation of fundamental value to price (growth stocks).

Academics and market practitioners use various indicators to distinguish value stocks from the growth stocks. Among them, the price-to-earnings ratio belongs to the most prominent. It compares the current price to the four-quarter (trailing or expected) net earnings. It was used in both the initial groundbreaking research (Basu 1977, De Bondt and Thaler 1985) and the most recent papers in the field (Cahine 2008). On the other hand, price-to-book ratio was significantly popularized by Fama and French $(1992,1993)$ and it is now probably the most commonly used indictor in 
the field (for instance Capaul et al .1993, Fama and French 1998, Black and McMillian 2006, Huang \& Yang 2008). Besides that, price-to-cash-flow (Fama and French 1998, Bauman et al. 1998, La Porta et al. 1997, Brown et al. 2008) and price-to-sales relations are commonly employed (Leledakis and Davidson 2001, Jeong et al. 2009)

The value premium is extensively documented in the literature. The first formal attempts to investigated were taken by Nicholson $(1960,1968)$, but the initial modern-type research is usually attributed to Basu $(1975,1977)$, who examined the price performance of P/E sorted portfolios of NYSE industrials between 1957 and 1971. Formal statistical evidence of the value effect were presented by Stattman (1980) and Rosenberg (1985). They used the book to market ratio as a value indicator. Davis et al. (1994) confirmed the value effect in US stock markets. Chan et al. (1991) and Capaul et al. (1993) confirmed the value effect, but in outside the US markets. The value effect was observed in stocks returns, Fama and French (1998, 2012), Rouwenhorst (1999), Lam (2002), Ghargohori (2009), Chui et al. (2010) and Asness et al. (2013).

The value factors are traditionally used to explain cross-sectional variation in their returns. However, I can observe some parallels at the macro level, as it turns out that the inter-country stock market returns can be forecasted basing on cross-country value factors. Although the evidence is not particularly abundant, the existing papers rather confirm the described phenomenon (Asness et al. 1997, Kouwenberg Salomons 2005, Bhojraj and Swaminathan 2006, Kim 2012). Garff (2013) analyzes a samples of 18 to 41 countries and find the evidence country-level value effect, however the research lacks formal statistical inferences. Ansess et al. (2013) on the contrary also find convincing statistical evidence, but includes only from 8 to 18 countries in the sample.

Although the presence of value premium in stock markets is currently rather undisputable, the answer why it actually exists is still controversial. There are generally two mainstream explanations: behavioural and neoclassical.

The neoclassical explanation links the value premium with time-varying relative risks, which are not directly attributable to the market risk expressed in beta (Fama and French 1993, 1995, 1996, Davis et al. 2000, Lettau and Ludvigson 2001, Zhang 2005, Campbell et al. 2009). The relative risks of value and growth stocks may vary with the business cycle with value stocks being riskier than growth stocks in economic downturns. List of models explaining theories on rational grounds may be found in Daniel and Titman (2012), Lewellen et al. (2006) and Phalippou (2007). Griffin and Lemmon (2002) find that firms with highest distress risk show a large value effect. Ali et al. (2005) noticed that the value premium is more concentrated in stocks with higher idiosyncratic volatility, which may be interpreted as a proxy for arbitrage. Jensen et al. (1997) argue that value companies are quite sensitive to macroeconomic conditions, e.g. interest rate risk or the business cycle. Petkova and Zhang (2005) argues that betas for value stocks have a positive covariance with the anticipated market-risk premium while the betas for growth stocks tend to perform inversely. Additionally, some papers analyzed the performance of value stocks in crisis conditions, which are associated with higher risk. Yamani and Swanson (2012) provide evidence, that the value stocks consistently performed more poorly than growth stocks during four selected financial crises - the international debt crisis, the ERM crisis, the Asian crisis, and the terrorist attack on September 11, 2001. Finally, Campbell and Cochrane suggest, that the value premium may result from a time-varying price of risk (1999). 
On the contrary, supporters of behavioral theories argue that the value premium is related to a time-varying relative mispricing, which stems from for example extrapolative expectations of investors. (De Bondt and Thaler 1985, Lakonishok et al. 1994, Daniel and Titman 1997, Daniel et al. 1998, Barberis and Shleifer 2003). The neoclassical hypothesis imply that the value premium should be somehow positively correlated with the business cycle (Carlson et al. 2004, Zhang 2005), but the empirical evidence is equivocal. Chen et al. 2008 finds negative correlation with the business cycle and Gulen et al. (2011) argues that the premium actually increases during economic downturns. Campello et al. (2008) estimate the expected value premium is countercyclical, corporate bond yields (a proxy for credit risk) does not matter. Montone (2012) comments that if the value stocks are countercyclical and provide insurance against real and financial shocks, thee should deliver lower risk-adjusted returns, which is obviously not true. Du (2011) shows that the value premium has little correlation with the Chicago Fed National Activity Index (CFNAI-MA3). He finds that while value premium is rather correlated with investor sentiment, it shows very little correlation with the state of the economy. Also Phalippou (2007) indicates that data are at odds with the neoclassical risk theories .

If the value-premium is time-varying (either cyclically or countercyclically), then there may exist some method to forecast it. On the one hand, some attempts in this field have been fairly successful so far. Asness et al. (2000) and Cohen et al. (2003) say that time-variation in return premium is predictable with specifically the value spread (the spread between the cut-off points of value and growth portfolios). Bauer and Molenar (2002) and Bauer et al. (2004) predict value premium based on a wide array of factors. Chen et al. (2008) and Li et al. (2013) use a transformed Gordon growth model to forecast the value factor. On the other hand, some other papers suggest that value premium is rather difficult to predict. Fama and French (2002) argue that unlike the equity premium, the vaulue premium is stable over time.

\section{Research and Methodology}

We investigate the issue of returns to value strategy as the explanation for variation in cross-sectional country returns using data from 66 different countries using two types of indices. First, I use the MSCI indices, which guarantee identical computational methodology along all the markets. Unfortunately, MSCI indices are not always easily replicable, what may seem not very practical from an investor perspective. Therefore, I perform another parallel research based on local indices, which in each case can be replicate at low cost with an passive ETF or in the futures market. In other words, I perform actually two similar analyses based on slightly different basic data. In case there is no data for one type of index in a given country, I use the index from the other group. The full list of country portfolios and benchmarks analyzed is presented in the appendices 2-3. The data on prices and fundamental factors come from Bloomberg.

First, I analyze the value returns in the international returns. I sort all the country portfolios in a given time on four popular value criteria: earnings yield, cash flow yield, sales to price ratio and book value to market value ratio:

- earnings yield (EP) - the sum of recent four quarters' earnings to current market value; 
- cash flow yield (CFP) - the sum of recent four quarters' free cash flows to current market value;

- sales to price ratio $(S P)$ - the sum of recent four quarters' sales to current market value;

- value factor (BVMV) - the book value to market value ratio.

Additionally, I compute a few additional non-value factor, which are indicative of the market situation and are used in the later stage of research:

- size factor (S) - the market capitalization of all the companies in the country portfolio;

- long-term momentum factor (LTM) - 12-month realized rate of return in the year preceding the portfolio formation;

- short-term momentum factor (STM) - 1-month realized rate of return in the month preceding the portfolio formation ${ }^{a}$.

We include a market in the sample only if at a given point of time only when I are able to compute the analyzed value factor (EP, CFP, SP or BVMV) and three accompanying additional factors (S, LTM and STM). Therefore, the number of indices in the sample grew along with the development of worldwide capital markets: from 47 in the beginning of the research period to 66 in the end in case of the MSCI indices, and from 24 to 66 in case of local indices. I use complete time-series data (encompassing all the described above) from the period 04/30/2000-10/31/2013. The exception is the CFP factor - in this case I use 12/31/2000-10/31/2013 due to lack of sufficient data. I do not analyze the earlier period because I feel that to small number of various countries in the sample could disturb the results. I perform all the computations based on monthly data. The detailed description of time-series used is exhibited in the appendices 3-4.

Based on value characteristic (EP, CFP, SP or BVMV), I form three separate portfolios for each factor including $30 \%$ of markets with the lowest factor, $30 \%$ of markets with the highest factor and the remaining $40 \%$ of the mid-markets. I use three equal weighting scheme.

Along with the factor portfolios, I calculate also returns on the market portfolio. As the proxy for market portfolio, I use capitalization weighted average of all the markets included in the research in a given period.

We perform all the computation in three distinct currency schemes: US dollars (USD), euros (EUR) and Japanese yens (JPY). In other words, I convert all the data to into USD, EUR and JPY, and deliver three versions of results. It is important to note that the choice of basic currency impacts the data in three important ways. First, the currency fluctuations influence the variation in returns and momentum. Second, the size of the market measured with capitalization may change, influencing the construction of size-sorted portfolios. Finally, the composition of the market portfolio is can differ slightly in case of each currency convention.

\footnotetext{
${ }^{a}$ The importance of both factors in asset pricing is extensively documented in the literature, for example size: Herrera and Lockwood (1994), Heston at al. (1999), Rouwenhorst (1999), Horowitz et al. 2000, Fama and French (1992, 1993, 2008, 2012), Michou et al. (2010) and momentum: Jagadeesh and Titman (1993), Asness (1994), Fama and French (1998, 2012), Rouwenhorst (1998), Liew and Vassalou (2000), Griffin, Ji, and Martin (2003), Grinblatt and Moskowitz (2004), Chui, Wei, and Titman (2010), Asness, Moskowitz, and Pedersen (2013).
} 
Next, I form fully collateralized market-neutral (MN) long/short portfolios mimicking behavior of certain value factors. The MN portfolios' construction are based on existing theoretical and empirical evidence in the field, so as to make them positively exposed to factor-related premiums. In other words, the portfolios are always $100 \%$ long the $30 \%$ of markets, which yield the highest risk-adjusted returns, $100 \%$ short the $30 \%$ of markets which yield the lowest risk-adjusted returns and $100 \%$ long the risk-free asset. As the result, I create 4 value collateralized market neutral long/short mimicking portfolio ("MN"), which are $100 \%$ long in the $30 \%$ highest $\mathrm{V}$ country portfolios, $100 \%$ short in the $30 \%$ lowest V country portfolios and $100 \%$ long the risk-free asset. As the value proxy I use the EP, CFP, SP and BVMV indicators. Again, similarly as in the previous case, the portfolios are equal weighted.

Finally, the performance of long/short MN portfolios is tested against four different models: zero model, market model, CAPM and Fama-French three factor modelb. Here, I base our computations on log-returns. The first one basically assumes that the expected return on security is zero, so I test whether the actual returns are statistically different form zero. The second model is the classical market model, as introduced by Fama et al. (1969):

$$
\begin{aligned}
& R_{i, t}=\alpha_{i}+\beta_{i} R_{m t}+\varepsilon_{i, t} \\
& E\left(\varepsilon_{i, t}\right)=0, \operatorname{var}\left(\varepsilon_{i, t}\right)=\sigma_{\varepsilon}^{2}
\end{aligned}
$$

where $R_{i t}$ and $R_{m t}$ are the period-t returns on security and the market portfolio, $\varepsilon_{i t}$ is the zero mean disturbance term and $\alpha_{i}, \beta_{i}$ and $\sigma_{\varepsilon^{\wedge} 2}$ are the parameters of the market model. Identically as in the earlier calculations, I use the valueweighted average of all markets.

The other model I employ is the Capital Asset Pricing Model (Sharpe 1964, 1966, Lintner 1965, Mossin 1966). The long/short portfolios' excess returns are regressed on market portfolio's excess returns, accordingly to the CAPM equation:

$$
R_{i, t}-R_{f t}=\alpha_{i}+\beta_{i}\left(R_{m t}-R_{f t}\right)+\varepsilon_{i, t},
$$

where $R_{i t}, R_{m t}$ and $R_{f t}$ are annual long/short portfolio, market portfolio and risk-free returns, and $\alpha_{i}$ and $\beta_{i}$ are regression parameters. I used 1-month BBA Libor USD to represent the risk-free rate as here I take only the USD approach. The $\alpha_{i}$ intercept measures the average annual abnormal return (so called Jensen-alpha). Finally, the last model is the FamaFrench three factor model (Fama \& French 1992, 1993):

$$
R_{i, t}=\alpha+R_{f}+\beta_{r m} \cdot\left(R_{m t}-R_{f}\right)+\beta_{S M B} \cdot S M B+\beta_{H M L} \cdot H M L+\varepsilon_{i t},
$$

where $\beta_{r m}, \beta_{S M B}, \beta_{H M L}$, and $\alpha$ ere the estimated parameters of the model. $\beta_{r m}$ is analogical to the CAPM beta, but it is not equal to it. The $\beta_{S M B}, \beta_{H M L}$ are exposed to $S M B H M L$ risk factors, which denote returns from zero-cost arbitrage

\footnotetext{
${ }^{\mathrm{b}}$ A more detailed review and description of expected return models can be found for example in Cambell, Lo \& MacKinlay (1997) and Cochrane (2005).
} 
portfolios, which are long US small-caps and short US large-caps (SMB), and long high BV/MV US stocks and short low BV/MV US stocks $(H M L)$. I use the factors computed by Kenneth French and available at his website ${ }^{\mathrm{c}}$.

In all the models, our zero hypothesis is that the alpha intercept is not statistically different from zero, and the alternative hypothesis states that it actually differs from zero. I find the equation parameters using OLS and test them in parametric way.

Having tested the factor performance, I analyze the interactions between the value factors (EP, CFP, SP, BVMV) and market characteristics (S, LTM, STM).All the computations are based on equal weighted MN portfolios (the market portfolios and risk-free rate are derived identically as befor). Based on the value factors (EP, CFP, SP, BVMV) and market characteristics (S, LTM, STM), I form double-sorted factor portfolios. I do it as follows. First, I ascribed each country portfolio to one of the subsamples based on the fundamental factors above: low $30 \%$, mid $40 \%$ or high $30 \%$. In other words, I segregate all the stocks into low, medium or high value factors (EP, CFP, SP, BVMV), low, medium or high S, low, medium or high LTM and low, medium or high STM. Secondly, I create nine portfolios for each pair combination of value factors $(\mathrm{V})$ and market characteristics. For instance, in case of pair $\mathrm{V}+\mathrm{S}$, I created low $\mathrm{V}$ and low $\mathrm{S}$ portfolio, which consisted of markets that belonged simultaneously to low V subgroup and low S subgroup; low V and medium S portfolio, which consisted of markets that belonged simultaneously to low V subgroup and medium $\mathrm{S}$ subgroup; and so on 7 other $\mathrm{V}+\mathrm{S}$ portfolios.

Next, I form market-neutral long/short portfolios for each of the pair combinations. The premises of certain long/short portfolios are based on existing previous theoretical and empirical evidence. Thus, I create following equal weighted portfolios:

- $100 \%$ long high EP, CFP, SP or BVMV and high LTM, 100\% short low EP, CFP, SP or BVMV and low LTM, $100 \%$ long the risk-free asset;

- $100 \%$ long high EP, CFP, SP or BVMV and high STM, 100\% short low EP, CFP, SP or BVMV and low STM, $100 \%$ long the risk-free asset;

- $100 \%$ long high EP, CFP, SP or BVMV and low S, 100\% short low EP, CFP, SP or BVMV and high S, 100\% long the risk-free asset.

For example, the first long/short portfolio is $100 \%$ long the country portfolios which belong at the same time to the high value and high long-term momentum subgroups, $100 \%$ short the country portfolios which belong at the same time to the low value and low long-term momentum subgroups and $100 \%$ long the risk-free asset. Finally, I test the described portfolios using identical procedures as described above against the zero, market model, CAPM and FamaFrench three factor model.

In the end, I test the connection between the returns to value factors and a series of fundamental variables related to market tensions and credit conditions. I regress the loreturns to value factors against changes in fundamental variables.

\footnotetext{
${ }^{\mathrm{c}} \mathrm{Http}: / /$ mba.tuck.dartmouth.edu/pages/faculty/ken.french/data_library.html
} 
I use to types of changes: absolute changes and nominal values and logarithmic changes (nepers), so I test two distinct models:

$$
\begin{aligned}
& R_{i, t}=\alpha_{i}+\beta_{i}\left(x_{j, t}-x_{j, t-1}\right)+\varepsilon_{i, t}, \\
& R_{i, t}=\alpha_{i}+\beta_{i} \ln \frac{x_{j, t}}{x_{j, t-1}}+\varepsilon_{i, t},
\end{aligned}
$$

where $R_{i, t}$ are $t$-period log-returns to zero-cost market neutral portfolios mimicking value factor $i, \alpha_{i}$ and $\beta_{i}$ are estimated model parameters, $\varepsilon_{i, t}$ is a zero mean disturbance term and $x_{j, t}$ is a value of a fundamental variable (a crisis proxy) $j$ in period $t$. I use all four previously examined value factors: EP, CFP, SP and BVMV. Moreover, I use five various market tensions' proxies, which refers to credit risk, market liquidity, volatility and general assessment of economic conditions. AAA and BAA spreads of US 10-year corporate bonds over 10-year US treasury bonds are proxies for the credit risk. As the representation of general financial market liquidity, I employ 3-month US TED spread, which is a difference between a 3-month US BBA Libor rate and a yield on US benchmark 3-month treasury bills. The expected market volatility is represented by VIX - the Chicago Board Options Exchange Market Volatility Index, a popular measure of the implied volatility of S\&P 500 index options. It is a measure indicating the market's expectation of stock market volatility over the next 30 day period. Finally, I also include the JP Morgan Global PMI Manufacturing Index. It is gauge of expected economic conditions based on the results of surveys covering over 10,000 purchasing executives in 32 countries. Together these countries account for an estimated almost $90 \%$ of global manufacturing output. The purpose of the last variable is to link the general assessment of the future economic situation with the value premium. Additionally, for the presentational purposes, I express their values in percentage points. It refers not only to VIX, BAA, AAA and TED, but also to PMI, which is divided by 100 , so it varies from 0 to $1(0 \%-100 \%)$. All the data come from Bloomberg. I estimate the model parameters using OLS and test them in a parametric way.

\section{Results and Discussion}

The tables 1 and 2 (appendix 1) exhibit the return characteristics of various value sorted portfolios. All the value factors - EP, CFP, SP and BVMV - seem to be important for portfolio formation. In case of each factor, the markets with high ratio deliver on average higher returns than both low ratio portfolios and the markets' average. This observation on the country portfolios' level is consistent with the previous research on the single companies' level. Additionally, all the described observations are robust to the choice of currency or representative index. Although the high value country portfolios always coincided with higher (measured both with standard deviation or beta), the superior risk-adjusted returns is confirmed by higher Sharpe (1994) and Treynor (1966) ratios (tables 3 and 4 , (appendix 1.)).

The tables 5 and 6 (appendix 1) reveal information about performance and its statistical significance of market neutral long/short factor mimicking portfolios. The three factors - EP, CFP and BVMV - yielded positive returns, which were 
generally significantly different from zero, no matter what currency or type of index I take into account. The last factor (SP) - as it can be presumed - also performed well, however the statistical significance were poorest.

The positive returns remain statistically significant after adjusting for risk in the market model and CAPM model. The last model employed, that some of the variation in returns of the cross-country returns may be explained by the FamaFrench factors. In the case of MSCI indices, generally the SMB factor was the most important one for all the value ratios with the exception of BVMV and SP. Here, what could be anticipated, the HML prevailed. What is interesting, this relationship holds in all the currency approaches, however not for local indices. In this case, the situations reverts and it is HML factor which seems to be more important. Generally, the alpha significance after applying Fama-French factors turns out to be rather weak. The only exception is the EP factor, which in some indices and currencies remains statistically significant. What is more, it is also the factor which yields the highest raw and market-adjusted returns. Again, it remains true in all currencies and index types. Finally, it should be noted, that it is impossible to settle whether the lack of significance is due to accidental results or only to short data series. The EP effect may actually suggest rather the latter.

The graphical presentation of returns to EP, CFP, SP and BVMV factors provide some additional interesting insights (figures 1 and 2, appendix 2). In all the currency and index regimes, the EP and CFP factors yielded more or less stable and positive returns during entire research period. However, the behavior of SP and BVMV factors can be split into two distinct phases. Before the years 2006-07, the rates of return were systematically positive, while later in years 2008-13 they turned negative. What is interesting here, it is not only the nature and sources of the variation, but also the fact, that the pattern may cast some doubt on the issue of sustainability of superior returns. Based on research in this paper, it cannot be settled, whether the strange two-phase pattern is just a coincidence, or does it suggest some structural changes which made the value and size factors stop working in years 2006-07 and later on.

The fact, that combinations of certain factors may result in attractive synergies, may be observed in tables 7 and 8 (appendix 1.). There generally two observations. First, value factors can be effectively combined with momentum factors. For instance, combination of top long-term performance markets and high EP markets yielded average monthly log-return of 1,24\% (MSCI USD approach). Second, the factors usually performed better in smaller markets. The same EP factor in the small MSCI markets yielded 0,99\% monthly log-returns on average. The results were generally similar across both index types. The superior risk-adjusted returns of the aforementioned combinations were confirmed by Sharpe and Treynor ratios (tables 9-10., appendix 1).

The formal statistical analysis yields results which vary across the currencies and index types, but which are more or less consistent with each other (tables 11-12, appendix 1). Generally, the factor combinations yielded positive returns and risk-adjusted returns, however not always statistically significant. Apparently, the best combinations seems to be EP in high momentum or small size markets. In these cases, the returns are positive and impressive even after applying the Fama-French methodology. What is more, the returns were higher than in case of standalone factors, which suggests that some synergies are present. Finally, it is noteworthy, the returns to the SP factor combined with the LTM factor are also statistically significant, although it does not work that well as a standalone factor. 
Finally, tables 13 and 14 (appendix 1) exhibit the OLS regression results. The performed computations reveal some interesting relations between the "perceived risk factors" and the time-variation in the inter-country value premium. First of all, the changes in the risk proxies commonly are correlated with the returns to value factor. The relation does not depend whether I use absolute or percentage (logarithmic) changes, but it generally stronger for quarterly data than for monthly data. Considering the quarterly data, the t-stats associated with regression coefficient are almost always higher than 2, and in some instances even than 4. The relation with AAA, BAA, TED and VIX is negative, which suggests that increases in this variables coincide with falling returns to value factor. The last variable here is the PMI and in its case the relation is inverse: the more PMI increases, the lower the value premiums. Naturally, it is a result of the construction of this index and it is consistent with the observations related to the remaining variables. It is also important to note, that the intercept usually remains statistically significant, which means that the variation in the perceived risk proxies does not fully account for the value premium. Finally, it is worth noting, that one the value proxies - the free cash flow to price ratio - does not exhibit the described properties. The reason why is not easy to find and remains beyond the scope of this paper.

Summing up, the regression analysis' results suggest, that increases (decreases) in the perceived non-market risk coincides with lower (higher) returns to value factor.

\section{Conclusions and Implications}

In this paper, I demonstrated that the value premium can be used to explain the cross-sectional variation in country returns. The inter-market value premium over past 14 years delivered significant positive risk-adjusted returns, no matter what type of ratio (P/E, P/CF, P/S, P/BV) I used, what functional currency I employed (EUR, USD, JPY) or what type of stock market index was taken as an input (MSCI or local stock exchange's index. Additionally, the value premium across countries can be successfully combined with other pricing factors, like market's size or inter-market momentum. Such double sorter portfolios historically performed even better.

Additionally, the paper contributes to the discussion on the source of the value premium. I demonstrate, that when the global indicators describing the market-wide risk perception (credit spreads, TED spreads, VIX volatility index, inverse PMI) rise, then the returns to value diminish. In other words, it appears, that when the investors regards the situation as fundamentally more risky, they withdraw money from the value markets and invest more eagerly in the growth markets. This observations supports the risk-based explanations of the value premium.

The inter-market value premium seems to be a relatively new phenomenon in the financial literature, therefore its sources and determinants are not entirely understood. Some further research should concentrate on finding the reasons why the country-level value premium is negatively correlated with the risk indicators, like credit spreads, TED spreads or volatility. Particularly, it is worth emphasizing, that this observation contradicts most research on the single stock level, which suggest, that the value premium is rather procyclical than countercyclical. Furthermore, additional research on the predictability of inter-country value premium and its relation with the business cycle should be done. 


\section{References}

Ali, A., L-S. Hwang, and M. Trombley (2003). Arbitrage risk and the book-to-market anomaly. Journal of Financial Economics, 69, 355-373.

Asness, C., J. Friedman, R. Krail, and J. Liew (2000). Style timing, Value versus growth. Journal of Portfolio Management, 26, 50-60.

Asness, C.S. (1994). Variables that Explain Stock Returns. Ph.D. Dissertation, University of Chicago.

Asness, C.S., J.M. Liew and R.L. Stievens (1997). Parallels Between the Cross-Sectional Predictability of Stocks and Country Returns. Journal of Portfolio Management, 23 (3), 78-87.

Asness, C.S.,T.J. Moskowitz and L.H. Pedersen (2013). Value and momentum everywhere. Journal of Finance, 68 (3), 929-985.

Ball, R., S.P Kothari and J. Shanken J. (1995). Problems in measuring portfolio performance, An application to contrarian investment strategies, Journal of Financial Economics,38, 79-107.

Barberis, N. and A. Shleifer (2003). Style investing. Journal of Financial Economics, 68 (2), 161-199. Zhang, L. 2005. The value premium. Journal of Finance 60 (1), 67-103.

Basu, S. (1975). The Information Content of Price-Earnings Ratios. Financial Management, 4 (2), 53-64.

Basu, S. (1977). The Investment Performance of Common Stocks in Relation to their Price-Earnings Ratio. Journal of Finance, 32 (3), 663-682.

Bauer R. and R. Molenaar (2002). Is the Value Premium Predictable in Real Time? Available at SSRN, http,//ssrn.com/abstract=321401 or http,//dx.doi.org/10.2139/ssrn.321401.

Bauer R., J. Derwall and R. Molenaar (2004). The real-time predictability of the size and value premium in Japan. Pacific-Basin Finance Journal, 12 (5), 503-523.

Bauman, W.S., C.M. Conover and R.E. Miller, 1998. Growth versus value and large-cap versus small-cap stocks in international markets. Financial Analysts Journal, 54 (2), 75-89.

Bhojraj, S. and B. Swaminathan (2006). Macromomentum: Returns Predictability in International Equity Indices, Journal of Business, 79(1), 429-451.

Black, A.J. and D.G. McMillan (2004). Non-linear predictability of value and growth stocks and economic activity, Journal of Business Finance \& Accounting, 31 (3), 439-474.

Brown, S., G.S. Rhee and L. Zhang (2008). The return to value in Asian stock markets, Emerging Markets Review, 9 , 194-205.

Cahine, S. (2008). Value versus growth stocks and earnings growth in style investing strategies in Euro-markets. Journal of Asset Management 9, 347-358.

Cambell, J.Y., A.W. Lo and A.C. MacKinlay (1997). The Econometrics of Financial Markets. Princeton University Press, Princeton, New Jersey, USA.

Campbell, J.Y., C. Polk and T. Vuolteenaho (2009). Growth or Glamour? Fundamentals and Systematic Risk in Stock Returns. Review of Financial Studies, 23 (1), 304-344. 
Campello, M., L. Chen, and L. Zhang (2008). Expected returns, yield spreads, and asset pricing tests. The Review of Financial Studies, 21 (3), 1297-1338.

Capaul, C., I. Rowley and W.F. Sharpe (1993). International value and growth stock returns, Financial Analysts Journal, 49 (1), 27-36.

Carlson, M., A. Fisher, and R. Giammarino (2004). Corporate Investment and Asset Price Dynamics: Implications for the Cross Section of Returns, Journal of Finance, 59 (6), 2577-2603.

Chan, L., N. Jegadeesh and J. Lakonishok (1995). Evaluating the Performance of Value versus Glamour Stocks, Journal of Financial Economics, 38, 269-296.

Chan, L.K.C, Y. Hamao and J. Lakonishok (1991). Fundamentals and stock returns in Japan. Journal of Finance, 46, 1739-1764.

Chen, L., R. Petkova, and L. Zhang (2008). The expected value premium. Journal of Financial Economics, 87 (2),269280.

Chui, A.C.W., S. Titman, K.C.J. Wei (2010). Individualism and momentum around the world. Journal of Finance, 65, 361-392.

Cochrane, J.C. (2005). Asset Pricing. Princeton University Press, Princeton, New Jersey, USA.

Cohen, R. B., C. Polk, and T. Vuolteenaho (2003). The value spread. Journal of Finance, 58 (2), 609-641.

Conrad, J., M. Cooper and G. Kaul (2003). Value versus glamour. Journal of Finance, 59, 1969- 1995.

Daniel, K. and S. Titman (1997). Evidence on the Characteristics of Cross Sectional Variation in Stock Returns, Journal of Finance, 52 (1), 1-33.

Daniel, K. and S. Titman (2012). Testing factor-model explanations of market anomalies. Critical Finance Review, 1(1), 103-139.

Daniel, K., D. Hirshleifer and A. Subrahmanyam (1998). Investor Psychology and Security Market Under- and Overreaction, Journal of Finance, 53 (6), 1839-1885.

Davis, J.L., E.F. Fama, and K.R. French (2000). Characteristics, Covariances, and Average Returns: 1929 to 1997. Journal of Finance, 55 (1), 389-406.

Davis, L.J. (1994). The cross-section of realized stock returns: The pre-COMPUSTAT evidence. Journal of Finance,49, 1579-1593.

De Bondt, W.F. M., and R. Thaler (1985). Does the Stock Market Overreact? Journal of Finance, 40 (3), 793-805.

Du, D. (2011). Value Premium and Investor Sentiment. Advances in Behavioral Finance \& Economics: The Journal of the Academy of Behavioral Finance, 1 (2), 87-101.

Fama, E. F. and K. R. French (2002). The equity premium. Journal of Finance, 57 (2), 637-659.

Fama, E.F. and K.R. French (1992). The cross-section of expected stock returns. Journal of Finance, 47, 427-466.

Fama, E.F. and K.R. French (1993). Common risk factors in the returns on stocks and bonds, Journal of Financial Economics, vol. 33, p. 3-56.

Fama, E.F. and K.R. French (1995). Size and Book-to-Market Factors in Earnings and Returns. Journal of Finance, 50 (1), 131-155. 
Fama, E.F. and K.R. French (1996). Multifactor Explanations of Asset Pricing Anomalies. Journal of Finance, 51 (1), $55-84$.

Fama, E. F. and K.R. French (1998). Value versus growth: the international evidence. Journal of Finance, 53 (6), 1975-1999.

Fama, E. F. and K.R. French (2008). Dissecting anomalies. Journal of Finance, 63 (4), 1653-1678.

Fama, E.F. and K.R. French (2012). Size, Value, and Momentum in International Stock Returns. Journal of Financial Economics, 105 (3), 457-472.

Fama, E.F., L. Fisher, M. Jensen and R. Roll (1969). The adjustment of stock prices to new information, International Economic Review, 10, 1-21.

Garff, D. (2013). Multi-Style Global Equity Investing: A Statistical Study on Combining Fundamentals, Momentum, Risk and Valuation for Improved Performance, Working paper, available at SSRN: http://ssrn.com/abstract=2367400. Gharghori, P., R. Lee and M. Veeraraghavan (2009). Anomalies and stock returns: Australian evidence. Accounting \& Finance, 49 (3), 555-576.

Graham, B. and D.L. Dodd (1934). Security Analysis. McGraw-Hill, New York, NY, United States.

Griffin, J., M. and M. Lemmon (2002). Book-to-Market Equity, Distress Risk, and Stock Returns. Journal of Finance, 57, 2317-2336.

Griffin, J.M., X. Ji and J.S. Martin (2003). Momentum investing and business cycle risk: Evidence from pole to pole. Journal of Finance, 58, 2515-2547.

Grinblatt, M. and T.J. Moskowitz (2004). Predicting Stock Price Movements from Past Returns: The Role of Consistency and Tax-Loss Selling. Journal of Financial Economics, 71, 541-579.

Gulen, H., Y. Xing and L. Zhang (2011).. Value versus Growth: Time-Varying Expected Stock Returns., Financial Management, 40 (2), 381-407.

Herrera, M. J. and L.J. Lockwood (1994). The size effect in the Mexican stock market. Journal of Banking and Finance, 18, $621-632$.

Heston, S. L., K.G. Rouwenhorst and R. E. Wessels (1999). The role of beta and size in the cross-section of european stock returns. European Financial Management, 5, 9 -27.

Hoekjan R. (2011). The performance of value vs. growth stocks during the financial crisis. Master Thesis, University of Twente, available online, http,//essay.utwente.n1/62263.

Horowitz, J.L., T. Loughran and N.E. Savin (2000). The disappearing size effect. Research in Economics, 54 (1), 83 100.

Huang, Y. and J. Yang (2008). Value premium in the Chinese stock market: free lunch or paid lunch? Applied Financial Economics, 23 (4), 315-324.

Jegadeesh, N. and S. Titman (1993). Returns to Buying Winners and Selling Losers: Implications for Stock Market Efficiency. Journal of Finance, 48 (1), 65-91.

Jensen, R.R. Johnson, and J.M. Mercer (1997). New Evidence on Size and Price-to-Book Effects in Stock Returns. Financial Analysts Journal, 53, 34-42. 
Jeong, J.G., , G. Lee and S. Mukherji (2009). Do Dow stocks offer a value premium? Journal of Wealth Management, $12(3), 95-103$.

Kim, D. (2012). Value Premium Across Countries. Journal of Portfolio Management, 38 (4), 75-86.

Kothari, S.P., J. Shanken, J. and R. Sloan (1995). Another look at the cross-section of expected stock returns. Journal of Finance, 50, 185-224.

Kouwenberg, R. and R. Salomons (2005). The Value Premium in Emerging Equity Markets and Local Macroeconomic Conditions. Working paper, available http://people.few.eur.n1/kouwenberg/Value\%20EM\%20Paper\%20v2.5b.pdf.

La Porta, R., J. Lakonishok, A. Shleifer and R.W. Vishny (1997). Good news for value stocks: further evidence on market efficiency, Journal of Finance, 52, 859-874.

Lakonishok, J., A. Shleifer, and R. W. Vishny (1994). Contrarian investment, extrapolation, and risk. Journal of Finance, 49 (5), 1541-1578.

Lam K. (2002). The relationship between size, book-to-market equity ratio, earnings-price ratio, and return for the Hong Kong stock market. Global Finance Journal, 13 (2), 163-179.

Leledakis, G. and I. Davidson (2001). Are Two Factors Enough? The U.K. Evidence. Financial Analyst Journal, 57 (6), 96-105.

Lettau, M. and S. Ludvigson (2001). Resurrecting the (C)CAPM: a Cross-Sectional Test when Risk Premia are TimeVarying, Journal of Political Economy, 109 (6), 1238-1287.

Lewellen, J., S. Nagel and J. Shanken (2006). A skeptical appraisal of asset-pricing tests. NBER working paper 12360. Li, Y., D. Ng and B. Swaminathan (2013). Predicting market returns using aggregate implied cost of capital. Journal of Financial Economics, 110 (2), 419-436.

Liew, J., and M. Vassalou M. (2000). Can Book-to-Market, Size and Momentum Be Risk Factors that Predict Economic Growth? Journal of Financial Economics, 57 (2), 221-245.

Lintner, J., 1965. The valuation of risk assets and the selection of risky investments in stock portfolios and capital budgets. Review of Economics and Statistics, 47, 13-37.

Lo, A.W., and S.C. MacKinlay (1990). Data-snooping biases in tests of financial asset pricing models. Review of Financial Studies 3, 431-468.

Michou, M., S. Mouselli and A. Stark (2010). Fundamental analysis and the modelling of normal returns in the UK, 2010, available at SSRN http://ssrn.com/abstract $=1607759$.

Montone, M. (2012). The Puzzling Countercyclicality of the Value Premium: Empirics and a Theory. Working paper, available at SSRN: http://ssrn.com/abstract=1970109.

Mossin, J. (1966). Equilibrium in a capital asset market. Econometrica, 34, 768-783.

Nicholson, S.F. (1960). Price-Earnings Ratios. Financial Analyst Journal, 16 (4), 43-45.

Nicholson, S.F. (1968). Price-Earnings Ratios in Relation to Investment Returns. Financial Analyst Journal, 24 (1), 105-109.

Petkova, R. and L. Zhang (2005). Is value riskier than growth? Journal of Financial Economics, 79, 187-202. 
Phalippou L. (2007). Can Risk-Based Theories Explain the Value Premium? Review of finance, 11 (2), 143-166.

Reinhart, C.M. and K.S. Rogoff (2009). This Time is Different: Eight Centuries of Financial Folly. Princeton University Press, Princeton, USA.

Rosenberg, B., K. Reid and R. Lanstein (1985). Persuasive evidence of market inefficiency. Journal of Portfolio Management, 11, 9-17.

Rouwenhorst, K. G. (1998). International momentum strategies. Journal of Finance, 53, 267-284.

Rouwenhorst, K.G. (1999). Local returns factors and turnover in emerging stock markets. Journal of Finance, 54, $1439-1464$.

Rouwenhorst, K.G. (1999). Local returns factors and turnover in emerging stock markets. Journal of Finance, 54, 1439-1464.

Sharpe, W.F. (1964). Capital asset prices: A theory of market equilibrium under conditions of risk. Journal of Finance $19,425-442$.

Sharpe, W.F. (1966). Mutual fund performance. Journal of Business, 39, 119-138.

Sharpe, W.F. (1994). The Sharpe Ratio. Journal of Portfolio Management, 21 (1), 49-58.

Stattman, D. (1980). Book values and stock returns. The Chicago MBA, Journal of Selected Papers, 4, 25-45.

Treynor, J.L. (1966). How to rate management investment funds. Harvard Business Review, 43, 63-75.

Yamani, E. and P. Swanson (2012). Financial Crises and Global Value Premium, Revisiting Fama-French. Wworking paper, available online, http//www.fma.org/Atlanta/Papers/YAMANI1.pdf. 


\section{Appendix 1. Tables.}

Table 1. Characteristics of factor sorted portfolios - MSCI indices

The table 1. presents the return characteristics of factor portfolios. Portfolios are sorted according to earnings yield ("EP”), cash flow yield ("CFP"), sales to price ratio ("SP") and book value to market value ratio ("BVMV"). "Return" is an average monthly log-return, "volatility" is a standard deviation of monthly log-returns, "beta" is regression coefficient calculated against a market portfolio. The market portfolio is computed as the capitalization weighted average of country portfolio returns. The data source is Bloomberg and the computations are based on listings from 66 countries during a period 04/30/2000-11/29/2013. The MSCI indices are used. The panels A, B and C exhibit results of computations with all the data converted to USD, EUR and JPY.

Panel A: data converted to USD.

\begin{tabular}{lccccccccc}
\hline & \multicolumn{2}{c}{ Returns } & \multicolumn{3}{c}{ Volatility } & \multicolumn{3}{c}{ Beta } \\
& low & mid & high & low & mid & high & low & mid & \multicolumn{1}{c}{ high } \\
\hline EP & $0,31 \%$ & $0,35 \%$ & $0,84 \%$ & $5,52 \%$ & $5,82 \%$ & $6,69 \%$ & 1,01 & 1,09 & 1,19 \\
CFP & $0,36 \%$ & $0,49 \%$ & $0,68 \%$ & $6,08 \%$ & $5,73 \%$ & $6,25 \%$ & 1,11 & 1,07 & 1,12 \\
SP & $0,26 \%$ & $0,62 \%$ & $0,56 \%$ & $5,48 \%$ & $6,30 \%$ & $6,31 \%$ & 0,96 & 1,19 & 1,13 \\
BVMV & $0,21 \%$ & $0,58 \%$ & $0,66 \%$ & $5,81 \%$ & $5,76 \%$ & $6,57 \%$ & 1,07 & 1,06 & 1,17 \\
\hline
\end{tabular}

Panel B: data converted to EUR.

\begin{tabular}{|c|c|c|c|c|c|c|c|c|c|}
\hline & \multicolumn{3}{|c|}{$\underline{\text { Returns }}$} & \multicolumn{3}{|c|}{ Volatility } & \multicolumn{3}{|c|}{ Beta } \\
\hline & low & mid & high & low & mid & high & low & mid & high \\
\hline EP & $0,08 \%$ & $0,12 \%$ & $0,62 \%$ & $4,70 \%$ & $4,82 \%$ & $5,73 \%$ & 0,95 & 1,00 & 1,09 \\
\hline CFP & $0,12 \%$ & $0,26 \%$ & $0,45 \%$ & $5,13 \%$ & $4,95 \%$ & $5,17 \%$ & 1,02 & 1,03 & 1,00 \\
\hline SP & $0,03 \%$ & $0,38 \%$ & $0,33 \%$ & $4,79 \%$ & $5,30 \%$ & $5,27 \%$ & 0,92 & 1,10 & 1,01 \\
\hline BVM V & $-0,02 \%$ & $0,35 \%$ & $0,43 \%$ & $5,06 \%$ & $4,72 \%$ & $5,61 \%$ & 1,04 & 0,95 & 1,07 \\
\hline
\end{tabular}

Panel C: data converted to JPY.

\begin{tabular}{|c|c|c|c|c|c|c|c|c|c|}
\hline & \multicolumn{3}{|c|}{$\underline{\text { Returns }}$} & \multicolumn{3}{|c|}{ Volatility } & \multicolumn{3}{|c|}{ Beta } \\
\hline & low & mid & high & low & mid & high & low & mid & high \\
\hline EP & $0,28 \%$ & $0,32 \%$ & $0,82 \%$ & $6,36 \%$ & $6,65 \%$ & $7,40 \%$ & 1,01 & 1,07 & 1,14 \\
\hline CFP & $0,33 \%$ & $0,46 \%$ & $0,65 \%$ & $6,85 \%$ & $6,59 \%$ & $6,98 \%$ & 1,08 & 1,06 & 1,08 \\
\hline SP & $0,23 \%$ & $0,59 \%$ & $0,52 \%$ & $6,29 \%$ & $7,05 \%$ & $7,12 \%$ & 0,96 & 1,13 & 1,10 \\
\hline BVM V & $0,18 \%$ & $0,55 \%$ & $0,63 \%$ & $6,60 \%$ & $6,55 \%$ & $7,36 \%$ & 1,05 & 1,04 & 1,14 \\
\hline
\end{tabular}


Table 2. Characteristics of factor sorted portfolios - local indices

The table 2. presents the return characteristics of factor portfolios. Portfolios are sorted according to earnings yield ("EP"), cash flow yield ("CFP"), sales to price ratio ("SP") and book value to market value ratio ("BVMV"). "Return" is an average monthly log-return, "volatility" is a standard deviation of monthly log-returns, "beta" is regression coefficient calculated against a market portfolio. The market portfolio is computed as the capitalization weighted average of country portfolio returns. The data source is Bloomberg and the computations are based on listings from 66 countries during a period 01/31/2000-11/29/2013 (12/31/2000-11/29/2013 for CFP). The local indices are used. The panels A, B and C exhibit results of computations with all the data converted to USD, EUR and JPY.

Panel A: data converted to USD.

\begin{tabular}{lccccccccr}
\hline & \multicolumn{2}{c}{ Returns } & \multicolumn{3}{c}{ Volatility } & \multicolumn{3}{c}{ Beta } \\
& low & mid & high & low & mid & high & low & mid & high \\
\hline EP & $0,24 \%$ & $0,33 \%$ & $0,76 \%$ & $5,62 \%$ & $5,81 \%$ & $6,74 \%$ & 1,02 & 1,08 & 1,21 \\
CFP & $0,27 \%$ & $0,46 \%$ & $0,70 \%$ & $6,18 \%$ & $5,93 \%$ & $6,22 \%$ & 1,13 & 1,09 & 1,12 \\
SP & $0,32 \%$ & $0,44 \%$ & $0,59 \%$ & $5,43 \%$ & $6,14 \%$ & $6,43 \%$ & 0,97 & 1,14 & 1,18 \\
BVMV & $0,22 \%$ & $0,58 \%$ & $0,65 \%$ & $5,80 \%$ & $5,85 \%$ & $6,66 \%$ & 1,06 & 1,08 & 1,19 \\
\hline
\end{tabular}

Panel B: data converted to EUR.

\begin{tabular}{lcccccccrr}
\hline & \multicolumn{2}{c}{ Returns } & \multicolumn{3}{c}{ Volatility } & \multicolumn{3}{c}{ Beta } \\
& low & mid & high & low & mid & high & low & mid & high \\
\hline EP & $0,09 \%$ & $0,22 \%$ & $0,59 \%$ & $4,89 \%$ & $4,85 \%$ & $5,47 \%$ & 0,96 & 0,98 & 1,03 \\
CFP & $0,09 \%$ & $0,32 \%$ & $0,56 \%$ & $5,18 \%$ & $4,94 \%$ & $5,15 \%$ & 1,05 & 1,02 & 1,00 \\
SP & $0,16 \%$ & $0,32 \%$ & $0,47 \%$ & $4,73 \%$ & $5,04 \%$ & $5,33 \%$ & 0,93 & 1,00 & 1,03 \\
BVMV & $0,12 \%$ & $0,36 \%$ & $0,45 \%$ & $4,80 \%$ & $4,75 \%$ & $5,58 \%$ & 0,96 & 0,96 & 1,05 \\
\hline
\end{tabular}

Panel C: data converted to JPY.

\begin{tabular}{|c|c|c|c|c|c|c|c|c|c|}
\hline & \multicolumn{3}{|c|}{$\underline{\text { Returns }}$} & \multicolumn{3}{|c|}{$\underline{\text { Volatility }}$} & \multicolumn{3}{|c|}{$\underline{\text { Beta }}$} \\
\hline & low & mid & high & low & mid & high & low & mid & high \\
\hline EP & $0,34 \%$ & $0,37 \%$ & $0,83 \%$ & $6,52 \%$ & $6,59 \%$ & $7,28 \%$ & 1,01 & 1,04 & 1,12 \\
\hline CFP & $0,26 \%$ & $0,49 \%$ & $0,72 \%$ & $6,93 \%$ & $6,67 \%$ & $7,05 \%$ & 1,07 & 1,04 & 1,07 \\
\hline SP & $0,26 \%$ & $0,48 \%$ & $0,43 \%$ & $6,06 \%$ & $7,00 \%$ & $7,22 \%$ & 0,94 & 1,11 & 1,14 \\
\hline BVMV & $0,31 \%$ & $0,57 \%$ & $0,65 \%$ & $6,42 \%$ & $6,59 \%$ & $7,31 \%$ & 1,01 & 1,05 & 1,12 \\
\hline
\end{tabular}


Table 3. Performance of factor sorted portfolios - MSCI indices.

The table 3. presents two popular performance measures of factor portfolios: Sharpe ratio and Treynor ratio. All the measures are presented on annualised basis and computed based on log-returns according to formulas described in the manuscript. Portfolios are sorted according to earnings yield ("EP"), cash flow yield ("CFP"), sales to price ratio ("SP") and book value to market value ratio ("BVMV"). The market portfolio is computed as the capitalization weighted-average of country portfolio returns. As the proxy for the money market returns, I use 1-month bids for BBA Libor USD, Euribor and Tibor for USD, EUR and JPY approaches. The data source is Bloomberg and the calculations are based on listings from 66 countries during a period 04/30/2000-11/29/2013. The MSCI indices are used. The panels A, B and C exhibit results of computations with all the data converted to USD, EUR and JPY.

Panel A: data converted to USD.

\begin{tabular}{lrrrrrr}
\hline & \multicolumn{2}{c}{ Sharpe ratio } & \multicolumn{3}{c}{ Treynor ratio } \\
& \multicolumn{1}{c}{ low } & \multicolumn{1}{c}{ mid } & \multicolumn{1}{c}{ high } & low & mid & \multicolumn{1}{l}{ high } \\
\hline EP & 0,08 & 0,10 & 0,34 & $1,53 \%$ & $1,79 \%$ & $6,62 \%$ \\
CFP & 0,10 & 0,18 & 0,27 & $1,86 \%$ & $3,43 \%$ & $5,27 \%$ \\
SP & 0,04 & 0,24 & 0,20 & $0,89 \%$ & $4,39 \%$ & $3,94 \%$ \\
BVMV & 0,01 & 0,24 & 0,25 & $0,28 \%$ & $4,45 \%$ & $4,85 \%$ \\
\hline
\end{tabular}

Panel B: data converted to EUR

\begin{tabular}{|c|c|c|c|c|c|c|}
\hline & \multicolumn{3}{|c|}{$\underline{\text { Sharpe ratio }}$} & \multicolumn{3}{|c|}{$\underline{\text { Treynor ratio }}$} \\
\hline & low & mid & high & low & mid & high \\
\hline EP & $-0,08$ & $-0,06$ & 0,25 & $-1,41 \%$ & $-0,94 \%$ & $4,66 \%$ \\
\hline CFP & $-0,05$ & 0,05 & 0,17 & $-0,87 \%$ & $0,82 \%$ & $3,11 \%$ \\
\hline $\mathrm{SP}$ & $-0,12$ & 0,12 & 0,09 & $-2,15 \%$ & $2,05 \%$ & $1,64 \%$ \\
\hline BVMV & $-0,14$ & 0,11 & 0,14 & $-2,47 \%$ & $1,98 \%$ & $2,61 \%$ \\
\hline
\end{tabular}

Panel C: data converted to JPY.

\begin{tabular}{lrrrrrr}
\hline & \multicolumn{2}{c}{ Sharpe ratio } & \multicolumn{3}{c}{ Treynor ratio } \\
& \multicolumn{1}{c}{ low } & \multicolumn{1}{c}{ mid } & \multicolumn{1}{c}{ high } & \multicolumn{1}{l}{ low } & \multicolumn{1}{l}{ mid } & \multicolumn{1}{l}{ high } \\
\hline EP & 0,14 & 0,15 & 0,38 & $3,07 \%$ & $3,32 \%$ & $8,48 \%$ \\
CFP & 0,15 & 0,23 & 0,31 & $3,40 \%$ & $5,02 \%$ & $7,01 \%$ \\
SP & 0,11 & 0,28 & 0,24 & $2,59 \%$ & $6,07 \%$ & $5,44 \%$ \\
BVMV & 0,08 & 0,28 & 0,29 & $1,83 \%$ & $6,15 \%$ & $6,42 \%$ \\
\hline
\end{tabular}


Table 4. Performance of factor sorted portfolios - local indices

The table 4. presents two popular performance measures of factor portfolios: Sharpe ratio and Treynor ratio. All the measures are presented on annualised basis and computed based on log-returns according to formulas described in the manuscript. Portfolios are sorted according to earnings yield ("EP"), cash flow yield ("CFP"), sales to price ratio ("SP") and book value to market value ratio ("BVMV"). The market portfolio is computed as the capitalization weighted average of country portfolio returns. As the proxy for the money market returns, I use 1-month bids for BBA Libor USD, Euribor and Tibor for USD, EUR and JPY approaches. The data source is Bloomberg and the calculations are based on listings from 66 countries during a period 01/31/2000-11/29/2013 (12/31/2000-11/29/2013 for CFP). The local indices are used. The panels A, B and C exhibit results of computations with all the data converted to USD, EUR and JPY.

Panel A: data converted to USD.

\begin{tabular}{|c|c|c|c|c|c|c|}
\hline & \multicolumn{3}{|c|}{ Sharpe ratio } & \multicolumn{3}{|c|}{ Treynor ratio } \\
\hline & low & mid & high & low & mid & high \\
\hline$\overline{\mathrm{EP}}$ & 0,03 & 0,09 & 0,30 & $0,63 \%$ & $1,65 \%$ & $5,70 \%$ \\
\hline CFP & 0,06 & 0,17 & 0,30 & $1,08 \%$ & $3,26 \%$ & $5,76 \%$ \\
\hline SP & 0,09 & 0,15 & 0,22 & $1,72 \%$ & $2,71 \%$ & $4,12 \%$ \\
\hline BVMV & 0,02 & 0,23 & 0,24 & $0,37 \%$ & $4,32 \%$ & $4,68 \%$ \\
\hline
\end{tabular}

Panel B: data converted to EUR.

\begin{tabular}{lcrrrrr}
\hline & \multicolumn{2}{c}{ Sharpe ratio } & \multicolumn{3}{c}{ Treynor ratio } \\
& low & mid & \multicolumn{1}{c}{ high } & low & mid & \multicolumn{1}{l}{ high } \\
\hline EP & $-0,07$ & 0,02 & 0,25 & $-1,28 \%$ & $0,26 \%$ & $4,58 \%$ \\
CFP & $-0,06$ & 0,10 & 0,25 & $-1,06 \%$ & $1,64 \%$ & $4,56 \%$ \\
SP & $-0,03$ & 0,09 & 0,18 & $-0,45 \%$ & $1,56 \%$ & $3,14 \%$ \\
BVMV & $-0,06$ & 0,12 & 0,16 & $-0,99 \%$ & $2,11 \%$ & $2,97 \%$ \\
\hline
\end{tabular}

Panel C: data converted to JPY.

\begin{tabular}{lrrrrrr}
\hline & \multicolumn{2}{c}{ Sharpe ratio } & & \multicolumn{2}{c}{ Treynor ratio } & \\
& \multicolumn{1}{c}{ low } & \multicolumn{1}{c}{ mid } & \multicolumn{1}{c}{ high } & low & \multicolumn{1}{l}{ mid } & \multicolumn{1}{l}{ high } \\
\hline EP & 0,17 & 0,18 & 0,38 & $3,82 \%$ & $4,01 \%$ & $8,64 \%$ \\
CFP & 0,12 & 0,24 & 0,34 & $2,67 \%$ & $5,44 \%$ & $7,86 \%$ \\
SP & 0,13 & 0,23 & 0,19 & $3,01 \%$ & $5,03 \%$ & $4,27 \%$ \\
BVMV & 0,16 & 0,29 & 0,30 & $3,46 \%$ & $6,27 \%$ & $6,82 \%$ \\
\hline
\end{tabular}


Table 5. Performance of market-neutral factor mimicking portfolios - MSCI indices

The table 5. presents return characteristics of market-neutral factor mimicking portfolios. Portfolios are created based on earnings yield ("EP"), cash flow yield ("CFP"), sales to price ratio ("SP") and book value to market value ratio ("BVMV"). "Return" is the average annual geometric rate of return and "volatility" is an annual standard deviation of log-returns. HML, SMB, $\alpha$ and $\beta$ are model parameters computed in each case according to the model' specification. I use log-returns in all computations. Data on HML and SML factors comes from Kenneth's R. French website. The market portfolio is computed as the capitalization weighted average of country portfolio returns. As the proxy for the money market returns, I use 1month bids for BBA Libor USD, Euribor and Tibor for USD, EUR and JPY approaches. Numbers in brackets below denote the statistical significance (t-stat). The data source is Bloomberg and the calculations are based on listings from 66 countries during a period 04/30/200011/29/2013. The MSCI indices are used. The panels A, B and C exhibit results of computations with all the data converted to USD, EUR and JPY.

Panel A: data converted to USD.

\begin{tabular}{|c|c|c|c|c|c|c|c|c|c|c|}
\hline & \multicolumn{2}{|c|}{ Zero model } & \multicolumn{2}{|c|}{ Market model } & \multicolumn{2}{|c|}{ CAPM } & \multicolumn{4}{|c|}{ Fama-French three factor model } \\
\hline & Return & Volatility & $\beta$ & $\alpha$ & $\beta$ & $\alpha$ & HML & SMB & $\beta$ & $\alpha$ \\
\hline \multirow[t]{2}{*}{ EP } & $0,75 \%$ & $2,71 \%$ & 0,16 & $0,72 \%$ & 0,17 & $0,56 \%$ & 0,04 & 0,15 & 0,13 & $0,48 \%$ \\
\hline & $(3,51)$ & & $(4,12)$ & $(3,53)$ & $(4,20)$ & $(2,79)$ & $(0,66)$ & $(1,90)$ & $(3,04)$ & $(2,34)$ \\
\hline \multirow[t]{2}{*}{ CFP } & $0,49 \%$ & $2,39 \%$ & 0,01 & $0,49 \%$ & 0,01 & $0,30 \%$ & 0,02 & 0,16 & $-0,02$ & $0,22 \%$ \\
\hline & $(2,61)$ & & $(0,29)$ & $(2,59)$ & $(0,35)$ & $(1,63)$ & $(0,39)$ & $(2,26)$ & $(-0,54)$ & $(1,16)$ \\
\hline \multirow[t]{2}{*}{ SP } & $0,48 \%$ & $3,20 \%$ & 0,16 & $0,45 \%$ & 0,16 & $0,30 \%$ & 0,13 & 0,09 & 0,12 & $0,20 \%$ \\
\hline & $(1,92)$ & & $(3,39)$ & $(1,86)$ & $(3,44)$ & $(1,22)$ & $(1,91)$ & $(0,98)$ & $(2,33)$ & $(0,83)$ \\
\hline \multirow[t]{2}{*}{ BVM V } & $0,64 \%$ & $2,93 \%$ & 0,09 & $0,62 \%$ & 0,09 & $0,45 \%$ & 0,22 & 0,21 & 0,01 & $0,27 \%$ \\
\hline & $(2,77)$ & & $(1,99)$ & $(2,72)$ & $(2,05)$ & $(1,99)$ & $(3,46)$ & $(2,44)$ & $(0,24)$ & $(1,25)$ \\
\hline
\end{tabular}

Panel B: data converted to EUR.

\begin{tabular}{|c|c|c|c|c|c|c|c|c|c|c|}
\hline & \multicolumn{2}{|c|}{ Zero model } & \multicolumn{2}{|c|}{ Market model } & \multicolumn{2}{|c|}{ CAPM } & \multicolumn{4}{|c|}{ Fama-French three factor model } \\
\hline & Return & Volatility & $\beta$ & $\alpha$ & $\beta$ & $\alpha$ & HML & SMB & $\beta$ & $\alpha$ \\
\hline \multirow[t]{2}{*}{ EP } & $0,75 \%$ & $2,72 \%$ & 0,13 & $0,75 \%$ & 0,13 & $0,58 \%$ & 0,06 & 0,18 & 0,09 & $0,47 \%$ \\
\hline & $(3,48)$ & & $(2,73)$ & $(3,58)$ & $(2,91)$ & $(2,79)$ & $(1,06)$ & $(2,17)$ & $(1,73)$ & $(2,20)$ \\
\hline \multirow[t]{2}{*}{ CFP } & $0,50 \%$ & $2,38 \%$ & $-0,02$ & $0,50 \%$ & $-0,01$ & $0,30 \%$ & 0,02 & 0,17 & $-0,05$ & $0,21 \%$ \\
\hline & $(2,69)$ & & $(-0,51)$ & $(2,68)$ & $(-0,34)$ & $(1,64)$ & $(0,44)$ & $(2,41)$ & $(-1,23)$ & $(1,09)$ \\
\hline \multirow[t]{2}{*}{ SP } & $0,47 \%$ & $3,21 \%$ & 0,09 & $0,47 \%$ & 0,09 & $0,30 \%$ & 0,17 & 0,15 & 0,03 & $0,15 \%$ \\
\hline & $(1,86)$ & & $(1,52)$ & $(1,88)$ & $(1,65)$ & $(1,18)$ & $(2,40)$ & $(1,56)$ & $(0,48)$ & $(0,59)$ \\
\hline \multirow[t]{2}{*}{ BVMV } & $0,62 \%$ & $2,96 \%$ & 0,03 & $0,63 \%$ & 0,03 & $0,44 \%$ & 0,24 & 0,24 & $-0,06$ & $0,21 \%$ \\
\hline & $(2,69)$ & & $(0,52)$ & $(2,69)$ & $(0,66)$ & $(1,89)$ & $(3,85)$ & $(2,87)$ & $(-1,18)$ & $(0,95)$ \\
\hline
\end{tabular}

Panel C: data converted to JPY.

\begin{tabular}{|c|c|c|c|c|c|c|c|c|c|c|}
\hline & \multicolumn{2}{|c|}{ Zero model } & \multicolumn{2}{|c|}{ Market model } & \multicolumn{2}{|c|}{ CAPM } & \multicolumn{4}{|c|}{ Fama-French three factor model } \\
\hline & Return & Volatility & $\beta$ & $\alpha$ & $\beta$ & $\alpha$ & HML & SMB & $\beta$ & $\alpha$ \\
\hline \multirow[t]{2}{*}{ EP } & $0,60 \%$ & $2,70 \%$ & 0,12 & $0,58 \%$ & 0,12 & $0,56 \%$ & 0,05 & 0,16 & 0,09 & $0,47 \%$ \\
\hline & $(2,83)$ & & $(3,53)$ & $(2,84)$ & $(3,55)$ & $(2,74)$ & $(0,86)$ & $(2,03)$ & $(2,37)$ & $(2,28)$ \\
\hline \multirow[t]{2}{*}{ CFP } & $0,33 \%$ & $2,37 \%$ & 0,01 & $0,33 \%$ & 0,01 & $0,31 \%$ & 0,03 & 0,16 & $-0,02$ & $0,23 \%$ \\
\hline & $(1,78)$ & & $(0,28)$ & $(1,76)$ & $(0,30)$ & $(1,65)$ & $(0,48)$ & $(2,25)$ & $(-0,59)$ & $(1,21)$ \\
\hline \multirow[t]{2}{*}{ SP } & $0,32 \%$ & $3,18 \%$ & 0,14 & $0,30 \%$ & 0,14 & $0,28 \%$ & 0,13 & 0,09 & 0,10 & $0,19 \%$ \\
\hline & $(1,27)$ & & $(3,41)$ & $(1,23)$ & $(3,42)$ & $(1,15)$ & $(1,92)$ & $(1,00)$ & $(2,33)$ & $(0,78)$ \\
\hline \multirow[t]{2}{*}{ BVMV } & $0,48 \%$ & $2,90 \%$ & 0,08 & $0,47 \%$ & 0,08 & $0,45 \%$ & 0,21 & 0,20 & 0,02 & $0,28 \%$ \\
\hline & $(2,10)$ & & $(2,18)$ & $(2,07)$ & $(2,20)$ & $(1,98)$ & $(3,43)$ & $(2,34)$ & $(0,46)$ & $(1,30)$ \\
\hline
\end{tabular}


Table 6. Performance of market-neutral factor mimicking portfolios - local indices

The table 6. presents return characteristics of market-neutral factor mimicking portfolios. Portfolios are created based on earnings yield ("EP"), cash flow yield ("CFP"), sales to price ratio ("SP") and book value to market value ratio ("BVMV"). "Return" is the average annual geometric rate of return and "volatility" is an annual standard deviation of log-returns. HML, SMB, $\alpha$ and $\beta$ are model parameters computed in each case according to the model' specification. I use log-returns in all computations. Data on HML and SML factors comes from Kenneth's R. French website. The market portfolio is computed as the capitalization weighted average of country portfolio returns. As the proxy for the money market returns, I use 1month bids for BBA Libor USD, Euribor and Tibor for USD, EUR and JPY approaches. Numbers in brackets below denote the statistical significance (t-stat). The data source is Bloomberg and the calculations are based on listings from 66 countries during a period 01/31/200011/29/2013 (12/31/2000-11/29/2013 for CFP). The local indices are used. The panels A, B and C exhibit results of computations with all the data converted to USD, EUR and JPY.

Panel A: data converted to USD.

\begin{tabular}{|c|c|c|c|c|c|c|c|c|c|c|}
\hline & \multicolumn{2}{|c|}{ Zero model } & \multicolumn{2}{|c|}{ Market model } & \multicolumn{2}{|c|}{ CAPM } & \multicolumn{4}{|c|}{ Fama-French three factor model } \\
\hline & Return & Volatility & $\beta$ & $\alpha$ & $\beta$ & $\alpha$ & HML & SMB & $\beta$ & $\alpha$ \\
\hline \multirow[t]{2}{*}{ EP } & $0,74 \%$ & $2,82 \%$ & 0,18 & $0,71 \%$ & 0,18 & $0,55 \%$ & 0,07 & 0,00 & 0,17 & $0,53 \%$ \\
\hline & $(3,32)$ & & $(4,29)$ & $(3,36)$ & $(4,37)$ & $(2,65)$ & $(1,08)$ & $(-0,05)$ & $(3,70)$ & $(2,48)$ \\
\hline \multirow[t]{2}{*}{ CFP } & $0,58 \%$ & $2,33 \%$ & $-0,01$ & $0,58 \%$ & $-0,01$ & $0,41 \%$ & 0,19 & 0,07 & $-0,06$ & $0,34 \%$ \\
\hline & $(3,09)$ & & $(-0,29)$ & $(3,09)$ & $(-0,21)$ & $(2,20)$ & $(2,92)$ & $(0,98)$ & $(-1,60)$ & $(1,81)$ \\
\hline \multirow[t]{2}{*}{ SP } & $0,47 \%$ & $2,72 \%$ & 0,20 & $0,44 \%$ & 0,20 & $0,29 \%$ & 0,13 & 0,01 & 0,18 & $0,24 \%$ \\
\hline & $(2,21)$ & & $(5,16)$ & $(2,20)$ & $(5,26)$ & $(1,46)$ & $(2,23)$ & $(0,13)$ & $(4,23)$ & $(1,18)$ \\
\hline \multirow[t]{2}{*}{ BVM V } & $0,63 \%$ & $2,76 \%$ & 0,12 & $0,61 \%$ & 0,12 & $0,45 \%$ & 0,18 & 0,18 & 0,05 & $0,30 \%$ \\
\hline & $(2,91)$ & & $(2,81)$ & $(2,88)$ & $(2,88)$ & $(2,12)$ & $(3,03)$ & $(2,28)$ & $(1,18)$ & $(1,43)$ \\
\hline
\end{tabular}

Panel B: data converted to EUR.

\begin{tabular}{|c|c|c|c|c|c|c|c|c|c|c|}
\hline & \multicolumn{2}{|c|}{ Zero model } & \multicolumn{2}{|c|}{ Market model } & \multicolumn{2}{|c|}{ CAPM } & \multicolumn{4}{|c|}{ Fama-French three factor model } \\
\hline & Return & Volatility & $\beta$ & $\alpha$ & $\beta$ & $\alpha$ & HML & SMB & $\beta$ & $\alpha$ \\
\hline \multirow[t]{2}{*}{ EP } & $0,68 \%$ & $2,89 \%$ & 0,06 & $0,68 \%$ & 0,07 & $0,50 \%$ & 0,12 & 0,11 & 0,03 & $0,39 \%$ \\
\hline & $(2,98)$ & & $(1,23)$ & $(3,00)$ & $(1,40)$ & $(2,20)$ & $(1,79)$ & $(1,28)$ & $(0,51)$ & $(1,71)$ \\
\hline \multirow[t]{2}{*}{ CFP } & $0,63 \%$ & $2,35 \%$ & $-0,05$ & $0,63 \%$ & $-0,04$ & $0,44 \%$ & 0,17 & 0,13 & $-0,10$ & $0,33 \%$ \\
\hline & $(3,32)$ & & $(-1,15)$ & $(3,33)$ & $(-0,96)$ & $(2,31)$ & $(2,79)$ & $(1,67)$ & $(-2,31)$ & $(1,74)$ \\
\hline \multirow[t]{2}{*}{ SP } & $0,49 \%$ & $2,67 \%$ & 0,09 & $0,50 \%$ & 0,10 & $0,32 \%$ & 0,17 & 0,09 & 0,05 & $0,21 \%$ \\
\hline & $(2,35)$ & & $(2,06)$ & $(2,39)$ & $(2,23)$ & $(1,55)$ & $(2,99)$ & $(1,09)$ & $(1,15)$ & $(1,00)$ \\
\hline \multirow[t]{2}{*}{ BVMV } & $0,54 \%$ & $2,69 \%$ & 0,08 & $0,54 \%$ & 0,08 & $0,36 \%$ & 0,22 & 0,15 & 0,02 & $0,20 \%$ \\
\hline & $(2,54)$ & & $(1,71)$ & $(2,57)$ & $(1,85)$ & $(1,73)$ & $(3,79)$ & $(1,90)$ & $(0,39)$ & $(0,97)$ \\
\hline
\end{tabular}

Panel C: data converted to JPY.

\begin{tabular}{|c|c|c|c|c|c|c|c|c|c|c|}
\hline & \multicolumn{2}{|c|}{ Zero model } & \multicolumn{2}{|c|}{ Market model } & \multicolumn{2}{|c|}{ CAPM } & \multicolumn{4}{|c|}{ Fama-French three factor model } \\
\hline & Return & Volatility & $\beta$ & $\alpha$ & $\beta$ & $\alpha$ & HML & SMB & $\beta$ & $\alpha$ \\
\hline \multirow[t]{2}{*}{ EP } & $0,52 \%$ & $2,76 \%$ & 0,10 & $0,50 \%$ & 0,10 & $0,48 \%$ & 0,09 & 0,02 & 0,08 & $0,44 \%$ \\
\hline & $(2,40)$ & & $(2,86)$ & $(2,37)$ & $(2,88)$ & $(2,28)$ & $(1,48)$ & $(0,21)$ & $(2,22)$ & $(2,06)$ \\
\hline \multirow[t]{2}{*}{ CFP } & $0,47 \%$ & $2,36 \%$ & 0,00 & $0,46 \%$ & 0,01 & $0,45 \%$ & 0,17 & 0,10 & $-0,04$ & $0,36 \%$ \\
\hline & $(2,45)$ & & $(0,15)$ & $(2,43)$ & $(0,17)$ & $(2,33)$ & $(2,69)$ & $(1,37)$ & $(-1,10)$ & $(1,91)$ \\
\hline \multirow[t]{2}{*}{ SP } & $0,22 \%$ & $2,77 \%$ & 0,18 & $0,20 \%$ & 0,18 & $0,18 \%$ & 0,16 & $-0,03$ & 0,16 & $0,13 \%$ \\
\hline & $(1,03)$ & & $(5,48)$ & $(0,98)$ & $(5,50)$ & $(0,89)$ & $(2,88)$ & $(-0,37)$ & $(4,51)$ & $(0,67)$ \\
\hline \multirow[t]{2}{*}{ BVM V } & $0,39 \%$ & $2,64 \%$ & 0,10 & $0,37 \%$ & 0,10 & $0,35 \%$ & 0,19 & 0,12 & 0,06 & $0,23 \%$ \\
\hline & $(1,88)$ & & $(3,05)$ & $(1,84)$ & $(3,06)$ & $(1,75)$ & $(3,44)$ & $(1,57)$ & $(1,58)$ & $(1,18)$ \\
\hline
\end{tabular}


Table 7. Value vs size and momentum factors - MSCI indices

The table 7. presents the return characteristics of portfolios constructed based on value criteria. Portfolios are sorted in two dimensions according to value factors (earnings yield ("EP"), cash flow yield ("CFP"), sales to price ratio ("SP") and book value to market value ratio ("BVMV") and market conditions (total market capitalization ("S"), long-term momentum ("LTM") and short-term momentum ("STM")). "Return" is an average monthly log-return, "volatility" is a standard deviation of monthly log-returns, "beta" is regression coefficient calculated against a market portfolio. The market portfolio is computed as the capitalization weighted average of country portfolio returns. The data source is Bloomberg and the computations are based on listings from 66 countries during a period 01/31/2000-11/29/2013 (12/31/2000-11/29/2013 for CFP). All the computations are performed in US dollars. The MSCI indices are used. The panels A, B, C and D exhibit results of analysis of the EP, CFP, SP and BVMV factors.

Panel A: EP factor.

\begin{tabular}{|c|c|c|c|c|c|c|c|c|c|}
\hline & & Return & & & Volatility & & & Beta & \\
\hline & & & Valu & te and long- & -term mome & intum & & & \\
\hline & LTM low & LTM mid & LTM high & LTM low & LTM mid & LTM high & LTM low & LTM mid & LTM high \\
\hline EP low & $-0,22 \%$ & $0,32 \%$ & $0,62 \%$ & $6,55 \%$ & $5,73 \%$ & $5,92 \%$ & 1,04 & 1,02 & 0,97 \\
\hline EP mid & $0,28 \%$ & $0,12 \%$ & $0,69 \%$ & $7,03 \%$ & $5,87 \%$ & $6,37 \%$ & 1,19 & 1,09 & 1,06 \\
\hline EP high & $0,59 \%$ & $0,71 \%$ & $1,24 \%$ & $7,48 \%$ & $6,83 \%$ & $6,75 \%$ & 1,27 & 1,14 & 0,99 \\
\hline
\end{tabular}

Value and short-term momentum

STM low STM mid STM high STM low STM mid STM high STM low STM mid STM high

\begin{tabular}{|c|c|c|c|c|c|c|c|c|c|}
\hline EP low & $0,29 \%$ & $0,38 \%$ & $0,32 \%$ & $6,63 \%$ & $5,59 \%$ & $7,78 \%$ & 1,05 & 1,00 & 0,98 \\
\hline EP mid & $0,34 \%$ & $0,41 \%$ & $0,18 \%$ & $6,36 \%$ & $6,12 \%$ & $5,97 \%$ & 1,10 & 1,14 & 1,02 \\
\hline EP high & $0,58 \%$ & $0,71 \%$ & $0,91 \%$ & $6,35 \%$ & $7,13 \%$ & $6,78 \%$ & 1,14 & 1,20 & 0,97 \\
\hline
\end{tabular}

\begin{tabular}{lrrrrrrrrr} 
& & & \multicolumn{9}{c}{ Value and size } \\
& S low & S mid & S high & S low & S mid & S high & S low & S mid & S high \\
\hline EP low & $0,42 \%$ & $0,35 \%$ & $0,09 \%$ & $6,16 \%$ & $6,55 \%$ & $5,79 \%$ & 0,82 & 1,10 & 1,08 \\
EP mid & $0,02 \%$ & $0,38 \%$ & $0,25 \%$ & $6,68 \%$ & $5,99 \%$ & $5,97 \%$ & 0,88 & 1,10 & 1,13 \\
EP high & $0,99 \%$ & $0,60 \%$ & $0,36 \%$ & $6,42 \%$ & $7,90 \%$ & $7,49 \%$ & 1,00 & 1,42 & 1,32 \\
\hline
\end{tabular}

Panel B: CFP factor.

\begin{tabular}{|c|c|c|c|c|c|c|c|c|c|}
\hline & \multicolumn{3}{|c|}{$\underline{\text { Return }}$} & \multicolumn{3}{|c|}{$\underline{\text { Volatility }}$} & \multicolumn{3}{|c|}{ Beta } \\
\hline \multicolumn{10}{|c|}{ Value and long-term momentum } \\
\hline & LTM low & LTM mid & LTM high & LTM low & LTM mid & LTM high & LTM low & LTM mid & LTM high \\
\hline CFP low & $-0,06 \%$ & $0,20 \%$ & $0,96 \%$ & $7,10 \%$ & $6,17 \%$ & $6,45 \%$ & 1,18 & 1,09 & 0,98 \\
\hline CFP mid & $0,07 \%$ & $0,44 \%$ & $0,83 \%$ & $7,21 \%$ & $5,73 \%$ & $6,19 \%$ & 1,17 & 1,05 & 1,05 \\
\hline CFP high & $0,49 \%$ & $0,52 \%$ & $0,99 \%$ & $7,25 \%$ & $6,52 \%$ & $6,57 \%$ & 1,16 & 1,14 & 0,99 \\
\hline \multicolumn{10}{|c|}{ Value and short-term momentum } \\
\hline & STM low & STM mid & STM high & STM low & STM mid & STM high & STM low & STM mid & STM high \\
\hline CFP low & $0,39 \%$ & $0,01 \%$ & $0,73 \%$ & $7,13 \%$ & $6,42 \%$ & $6,83 \%$ & 1,17 & 1,16 & 0,94 \\
\hline CFP mid & $0,45 \%$ & $0,57 \%$ & $0,18 \%$ & $6,54 \%$ & $5,94 \%$ & $6,17 \%$ & 1,14 & 1,09 & 1,04 \\
\hline CFP high & $0,54 \%$ & $0,65 \%$ & $0,78 \%$ & $6,54 \%$ & $6,54 \%$ & $6,50 \%$ & 1,17 & 1,15 & 1,01 \\
\hline \multicolumn{10}{|c|}{ Value and size } \\
\hline & S low & S mid & S high & S low & $\mathrm{S}$ mid & S high & S low & $\mathrm{S}$ mid & S high \\
\hline CFP low & $0,52 \%$ & $0,47 \%$ & $0,14 \%$ & $6,83 \%$ & $7,01 \%$ & $6,61 \%$ & 0,84 & 1,22 & 1,22 \\
\hline CFP mid & $0,81 \%$ & $0,53 \%$ & $0,24 \%$ & $6,14 \%$ & $6,17 \%$ & $5,78 \%$ & 0,91 & 1,13 & 1,09 \\
\hline CFP high & $0,90 \%$ & $0,52 \%$ & $0,14 \%$ & $6,29 \%$ & $7,14 \%$ & $6,41 \%$ & 0,99 & 1,25 & 1,18 \\
\hline
\end{tabular}


Panel C: SP factor.

\begin{tabular}{|c|c|c|c|c|c|c|c|c|c|}
\hline & & $\underline{\text { Return }}$ & & & Volatility & & & Beta & \\
\hline & & & Value & and long-te & $\mathrm{rm}$ moments & & & & \\
\hline & LTM low & LTM mid & LTM high & LTM low & LTM mid & LTM high & LTM low & LTM mid & LTM high \\
\hline$\overline{\text { SP low }}$ & $-0,11 \%$ & $0,15 \%$ & $0,83 \%$ & $6,34 \%$ & $5,87 \%$ & $6,31 \%$ & 0,96 & 1,01 & 0,96 \\
\hline SP mid & $0,32 \%$ & $0,52 \%$ & $0,96 \%$ & $7,32 \%$ & $6,35 \%$ & $6,58 \%$ & 1,26 & 1,18 & 1,13 \\
\hline SP high & $0,42 \%$ & $0,25 \%$ & $1,19 \%$ & $7,35 \%$ & $6,16 \%$ & $6,06 \%$ & 1,23 & 1,06 & 0,84 \\
\hline
\end{tabular}

Value and short-term momentum

STM low STM mid STM high STM low STM mid STM high STM low STM mid STM high

\begin{tabular}{llllllllll}
\hline SP low & $0,04 \%$ & $0,26 \%$ & $0,28 \%$ & $6,30 \%$ & $5,84 \%$ & $6,55 \%$ & 1,02 & 0,96 & 1,12 \\
SP mid & $0,75 \%$ & $0,68 \%$ & $0,26 \%$ & $6,99 \%$ & $6,21 \%$ & $6,72 \%$ & 1,23 & 1,14 & 1,19 \\
SP high & $0,52 \%$ & $0,39 \%$ & $0,57 \%$ & $6,38 \%$ & $6,78 \%$ & $6,45 \%$ & 1,13 & 1,23 & 0,96
\end{tabular}

Value and size

\begin{tabular}{lrrrrrrrrr} 
& S low & S mid & S high & S low & S mid & S high & S low & S mid & S high \\
\hline SP low & $0,23 \%$ & $0,14 \%$ & $-0,04 \%$ & $6,06 \%$ & $5,79 \%$ & $6,45 \%$ & 0,75 & 0,95 & 1,14 \\
SP mid & $0,53 \%$ & $0,55 \%$ & $0,54 \%$ & $6,94 \%$ & $6,94 \%$ & $6,16 \%$ & 1,12 & 1,28 & 1,17 \\
SP high & $0,92 \%$ & $0,77 \%$ & $0,09 \%$ & $6,29 \%$ & $7,86 \%$ & $6,27 \%$ & 0,89 & 1,41 & 1,17 \\
\hline
\end{tabular}

Panel D: BVMV factor.

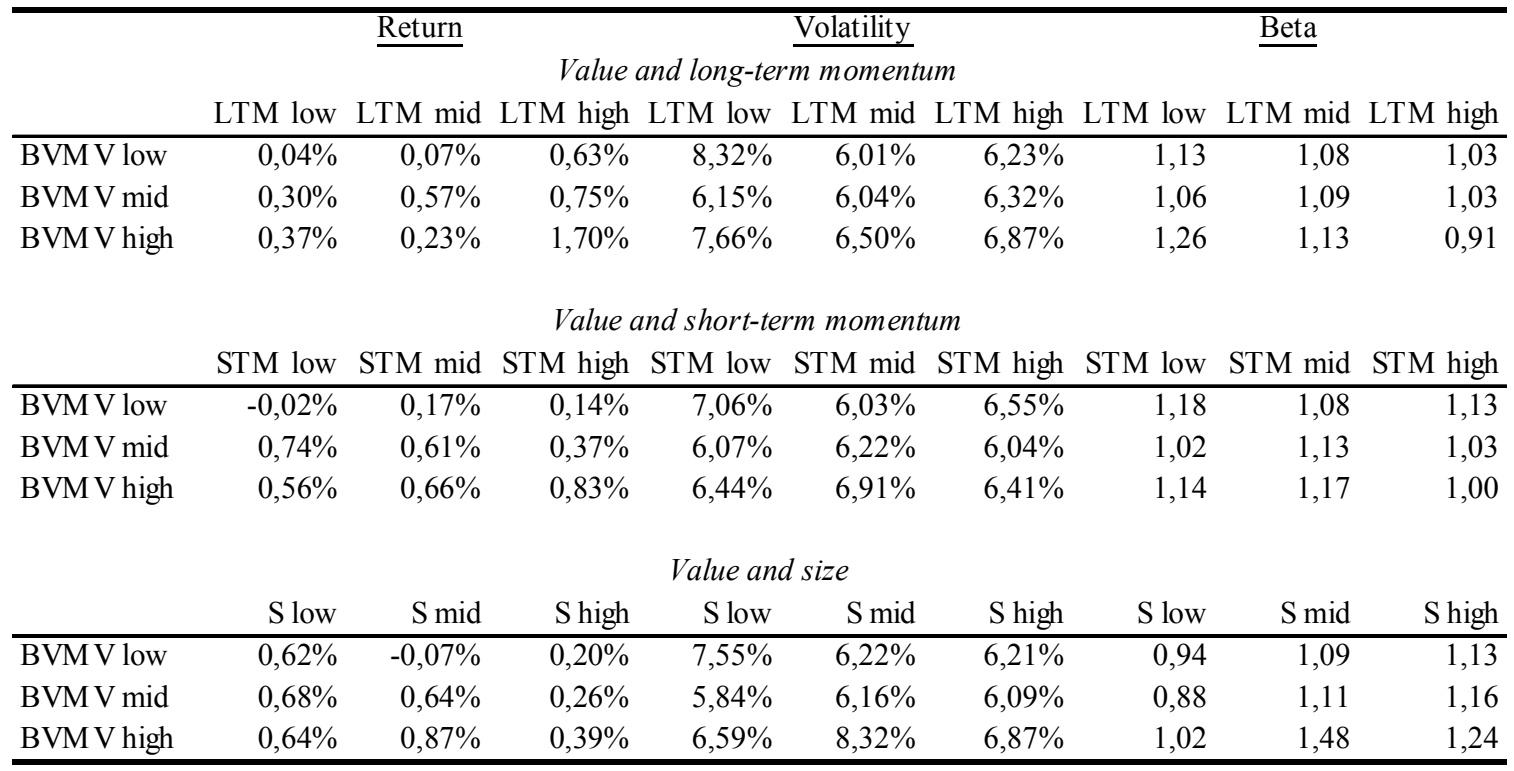


Table 8. Value vs size and momentum factors - local indices

The table 8. presents the return characteristics of portfolios constructed based on combinations of factors. Portfolios are sorted in two dimensions according to value factors (earnings yield ("EP"), cash flow yield ("CFP"), sales to price ratio ("SP") and book value to market value ratio ("BVMV") and market conditions (total market capitalization ("S"), long-term momentum ("LTM") and short-term momentum ("STM")). "Return" is an average monthly log-return, "volatility" is a standard deviation of monthly log-returns, "beta" is regression coefficient calculated against a market portfolio. The market portfolio is computed as the capitalization weighted average of country portfolio returns. The data source is Bloomberg and the computations are based on listings from 66 countries during a period 01/31/2000-11/29/2013 (12/31/2000-11/29/2013). The local indices are used. The panels A, B, C and D exhibit results of analysis of the EP, CFP, SP and BVMV factors.

Panel A: EP factor.

\begin{tabular}{|c|c|c|c|c|c|c|c|c|c|}
\hline & \multicolumn{3}{|c|}{$\underline{\text { Return }}$} & \multicolumn{3}{|c|}{ Volatility } & \multicolumn{3}{|c|}{ Beta } \\
\hline \multicolumn{10}{|c|}{ Value and long-term momentum } \\
\hline & LTM low & LTM mid & LTM high & LTM low & LTM mid & LTM high & LTM low & LTM mid & LTM high \\
\hline$\overline{\text { EP low }}$ & $0,01 \%$ & $0,14 \%$ & $0,41 \%$ & $7,01 \%$ & $5,76 \%$ & $6,14 \%$ & 1,12 & 0,95 & 0,99 \\
\hline EP mid & $0,05 \%$ & $0,32 \%$ & $0,55 \%$ & $6,74 \%$ & $5,79 \%$ & $6,27 \%$ & 1,14 & 1,07 & 1,05 \\
\hline EP high & $0,46 \%$ & $0,60 \%$ & $1,05 \%$ & $7,47 \%$ & $7,04 \%$ & $6,75 \%$ & 1,28 & 1,23 & 0,96 \\
\hline \multicolumn{10}{|c|}{ Value and short-term momentum } \\
\hline & STM low & STM mid & STM high & STM low & STM mid & STM high & STM low & STM mid & STM high \\
\hline$\overline{\text { EP low }}$ & $0,11 \%$ & $0,36 \%$ & $0,70 \%$ & $6,72 \%$ & $5,67 \%$ & $7,10 \%$ & 1,06 & 0,99 & 0,91 \\
\hline EP mid & $0,46 \%$ & $0,27 \%$ & $0,31 \%$ & $6,60 \%$ & $6,02 \%$ & $5,85 \%$ & 1,16 & 1,10 & 0,97 \\
\hline EP high & $0,49 \%$ & $0,48 \%$ & $1,01 \%$ & $6,27 \%$ & $7,16 \%$ & $6,96 \%$ & 1,14 & 1,26 & 1,03 \\
\hline \multicolumn{10}{|c|}{ Value and size } \\
\hline & S low & $\mathrm{S}$ mid & S high & S low & S mid & S high & S low & $\mathrm{S}$ mid & S high \\
\hline$\overline{\text { EP low }}$ & $0,29 \%$ & $0,41 \%$ & $0,11 \%$ & $6,15 \%$ & $7,35 \%$ & $5,52 \%$ & 0,88 & 1,20 & 1,01 \\
\hline EP mid & $0,36 \%$ & $0,24 \%$ & $0,34 \%$ & $6,36 \%$ & $6,07 \%$ & $6,04 \%$ & 0,95 & 1,07 & 1,14 \\
\hline EP high & $1,11 \%$ & $0,62 \%$ & $-0,02 \%$ & $7,05 \%$ & $7,25 \%$ & $7,07 \%$ & 1,09 & 1,31 & 1,28 \\
\hline
\end{tabular}

Panel B: CFP factor.

\begin{tabular}{|c|c|c|c|c|c|c|c|c|c|}
\hline & \multicolumn{3}{|c|}{ Return } & \multicolumn{3}{|c|}{ Volatility } & \multicolumn{3}{|c|}{ Beta } \\
\hline \multicolumn{10}{|c|}{ Value and long-term momentum } \\
\hline & LTM low & LTM mid & LTM high & LTM low & LTM mid & LTM high & LTM low & LTM mid & LTM high \\
\hline CFP low & $-0,11 \%$ & $-0,06 \%$ & $0,99 \%$ & $7,29 \%$ & $6,20 \%$ & $6,42 \%$ & 1,23 & 1,10 & 0,96 \\
\hline CFP mid & $0,24 \%$ & $0,41 \%$ & $0,78 \%$ & $7,19 \%$ & $6,00 \%$ & $6,52 \%$ & 1,17 & 1,09 & 1,09 \\
\hline CFP high & $0,38 \%$ & $0,40 \%$ & $1,10 \%$ & $7,32 \%$ & $6,74 \%$ & $6,19 \%$ & 1,22 & 1,17 & 0,93 \\
\hline \multicolumn{10}{|c|}{ Value and short-term momentum } \\
\hline & STM low & STM mid & STM high & STM low & STM mid & STM high & STM low & STM mid & STM high \\
\hline CFP low & $0,21 \%$ & $0,05 \%$ & $0,35 \%$ & $7,37 \%$ & $6,81 \%$ & $6,30 \%$ & 1,21 & 1,23 & 0,90 \\
\hline CFP mid & $0,53 \%$ & $0,27 \%$ & $0,63 \%$ & $6,65 \%$ & $6,01 \%$ & $6,36 \%$ & 1,11 & 1,09 & 1,05 \\
\hline CFP high & $0,54 \%$ & $0,66 \%$ & $0,72 \%$ & $6,34 \%$ & $6,56 \%$ & $6,45 \%$ & 1,14 & 1,13 & 0,99 \\
\hline \multicolumn{10}{|c|}{ Value and size } \\
\hline & S low & S mid & S high & S low & S mid & S high & S low & $\mathrm{S}$ mid & S high \\
\hline CFP low & $0,37 \%$ & $0,08 \%$ & $0,47 \%$ & $6,21 \%$ & $7,28 \%$ & $6,52 \%$ & 0,89 & 1,27 & 1,18 \\
\hline CFP mid & $0,67 \%$ & $0,47 \%$ & $0,30 \%$ & $7,05 \%$ & $6,34 \%$ & $5,83 \%$ & 1,07 & 1,12 & 1,09 \\
\hline CFP high & $1,05 \%$ & $0,60 \%$ & $0,21 \%$ & $6,40 \%$ & $6,94 \%$ & $6,52 \%$ & 0,99 & 1,21 & 1,20 \\
\hline
\end{tabular}


Panel C: SP factor.

\begin{tabular}{|c|c|c|c|c|c|c|c|c|c|}
\hline & \multicolumn{3}{|c|}{ Return } & \multicolumn{3}{|c|}{ Volatility } & \multicolumn{3}{|c|}{ Beta } \\
\hline \multicolumn{10}{|c|}{ Value and long-term momentum } \\
\hline & LTM low & LTM mid & LTM high & LTM low & LTM mid & LTM high & LTM low & LTM mid & LTM high \\
\hline SP low & $-0,09 \%$ & $0,13 \%$ & $1,03 \%$ & $7,33 \%$ & $5,70 \%$ & $6,39 \%$ & 1,03 & 1,01 & 0,98 \\
\hline SP mid & $0,43 \%$ & $0,41 \%$ & $0,57 \%$ & $6,84 \%$ & $6,24 \%$ & $6,51 \%$ & 1,17 & 1,14 & 1,10 \\
\hline SP high & $0,20 \%$ & $0,52 \%$ & $1,17 \%$ & $7,32 \%$ & $6,60 \%$ & $6,09 \%$ & 1,25 & 1,15 & 0,84 \\
\hline \multicolumn{10}{|c|}{ Value and short-term momentum } \\
\hline & STM low & STM mid & STM high & STM low & STM mid & STM high & STM low & STM mid & STM high \\
\hline SP low & $0,41 \%$ & $0,28 \%$ & $0,13 \%$ & $6,56 \%$ & $5,69 \%$ & $6,59 \%$ & 1,00 & 1,00 & $\overline{1,14}$ \\
\hline SP mid & $0,63 \%$ & $0,29 \%$ & $0,23 \%$ & $7,03 \%$ & $6,17 \%$ & $6,48 \%$ & 1,22 & 1,13 & 1,11 \\
\hline SP high & $0,52 \%$ & $0,44 \%$ & $1,00 \%$ & $6,38 \%$ & $6,79 \%$ & $6,86 \%$ & 1,14 & 1,21 & 1,09 \\
\hline \multicolumn{10}{|c|}{ Value and size } \\
\hline & S low & S mid & S high & S low & S mid & S high & S low & S mid & S high \\
\hline SP low & $0,39 \%$ & $0,30 \%$ & $0,26 \%$ & $6,46 \%$ & $5,67 \%$ & $5,93 \%$ & 0,87 & 0,92 & $\overline{1,09}$ \\
\hline SP mid & $0,49 \%$ & $0,48 \%$ & $0,38 \%$ & $6,52 \%$ & $6,50 \%$ & $6,29 \%$ & 1,02 & 1,18 & 1,18 \\
\hline SP high & $1,05 \%$ & $0,56 \%$ & $0,07 \%$ & $6,70 \%$ & $7,57 \%$ & $6,28 \%$ & 1,02 & 1,37 & 1,16 \\
\hline
\end{tabular}

Panel D: BVMV factor.

\begin{tabular}{lrrrrrrrrr}
\hline & \multicolumn{3}{c}{ Return } & \multicolumn{4}{c}{$\begin{array}{c}\text { Volatility } \\
\text { Value and long-term momentum }\end{array}$} \\
& \multicolumn{4}{c}{ LTM low } & LTM mid & LTM high & LTM low & LTM mid & \multicolumn{3}{c}{ LTM high LTM low } & LTM mid LTM high \\
\hline BVMV low & $0,16 \%$ & $0,07 \%$ & $0,69 \%$ & $7,33 \%$ & $6,04 \%$ & $6,37 \%$ & 1,06 & 1,09 & 1,03 \\
BVMV mid & $0,27 \%$ & $0,64 \%$ & $0,73 \%$ & $6,33 \%$ & $6,00 \%$ & $6,31 \%$ & 1,12 & 1,08 & 1,04 \\
BVMV high & $0,46 \%$ & $0,43 \%$ & $1,39 \%$ & $7,74 \%$ & $6,67 \%$ & $7,07 \%$ & 1,31 & 1,15 & 0,93
\end{tabular}

Value and short-term momentum

STM low STM mid STM high STM low STM mid STM high STM low STM mid STM high

\begin{tabular}{lrrrrrrrrr}
\hline BVM V low & $0,24 \%$ & $0,05 \%$ & $0,02 \%$ & $6,86 \%$ & $6,02 \%$ & $6,69 \%$ & 1,10 & 1,08 & 1,13 \\
BVM V mid & $0,89 \%$ & $0,44 \%$ & $0,45 \%$ & $6,11 \%$ & $6,15 \%$ & $6,23 \%$ & 1,06 & 1,12 & 1,04 \\
BVM V high & $0,60 \%$ & $0,64 \%$ & $0,66 \%$ & $6,54 \%$ & $6,78 \%$ & $6,77 \%$ & 1,16 & 1,17 & 1,05
\end{tabular}

Value and size

\begin{tabular}{lrrrrrrrrr} 
& S low & S mid & S high & S low & S mid & S high & S low & S mid & S high \\
\hline BVMV low & $0,67 \%$ & $0,07 \%$ & $0,20 \%$ & $8,98 \%$ & $6,27 \%$ & $6,07 \%$ & 1,10 & 1,10 & 1,11 \\
BVM V mid & $0,69 \%$ & $0,58 \%$ & $0,32 \%$ & $6,14 \%$ & $6,25 \%$ & $6,01 \%$ & 0,96 & 1,12 & 1,13 \\
BVMV high & $0,81 \%$ & $0,61 \%$ & $0,32 \%$ & $6,73 \%$ & $7,97 \%$ & $7,11 \%$ & 1,07 & 1,40 & 1,26 \\
\hline
\end{tabular}


Table 9. Performance of value portfolios vs size and momentum - MSCI indices.

The table 12. presents two popular performance measures (Sharpe ratio and Treynor ratio) of portfolios sorted on combination of two factors. All the measures are presented on annualised basis and computed based on log-returns according to formulas described in the manuscript. Portfolios are sorted according to value factors (earnings yield ("EP"), cash flow yield ("CFP”), sales to price ratio ("SP") and book value to market value ratio ("BVMV") and market conditions (total market capitalization ("S"), long-term momentum ("LTM") and short-term momentum ("STM")). The market portfolio is computed as the capitalization weighted-average of country portfolio returns. As the proxy for the money market returns, I use 1month bids for BBA Libor USD. The data source is Bloomberg and the calculations are based on listings from 66 countries during a period 04/30/2000-11/29/2013. The MSCI indices are used. The panels A, B, C and D exhibit results of analysis of the EP, CFP, SP and BVMV factors.

Panel A: EP factor.

\begin{tabular}{lrrrrrr}
\hline & \multicolumn{3}{c}{ Sharpe ratio } & \multicolumn{3}{c}{ Treynor ratio } \\
& & \multicolumn{2}{c}{ Value and long-term momentum } & & \\
& LTM low & LTM mid & LTM high & LTM low & LTM mid & LTM high \\
\hline EP low & $-0,21$ & 0,08 & 0,25 & $-4,6 \%$ & $1,5 \%$ & $5,4 \%$ \\
EP mid & 0,05 & $-0,04$ & 0,27 & $0,9 \%$ & $-0,8 \%$ & $5,7 \%$ \\
EP high & 0,19 & 0,27 & 0,54 & $3,8 \%$ & $5,5 \%$ & $12,8 \%$
\end{tabular}

Value and short-term momentum

\begin{tabular}{|c|c|c|c|c|c|c|}
\hline & STM low & STM mid & STM high & STM low & STM mid & STM high \\
\hline EP low & $\overline{0,06}$ & 0,12 & 0,06 & $1,2 \%$ & $2,3 \%$ & $1,6 \%$ \\
\hline EP mid & 0,08 & 0,13 & $-0,01$ & $1,7 \%$ & $2,4 \%$ & $-0,1 \%$ \\
\hline EP high & 0,21 & 0,25 & 0,37 & $4,1 \%$ & $5,2 \%$ & $9,0 \%$ \\
\hline
\end{tabular}

\begin{tabular}{|c|c|c|c|c|c|c|}
\hline \multicolumn{7}{|c|}{ Value and size } \\
\hline & S low & S mid & S high & S low & $\mathrm{S}$ mid & S high \\
\hline EP low & 0,13 & 0,09 & $-0,06$ & $3,5 \%$ & $1,8 \%$ & $-1,1 \%$ \\
\hline EP mid & $-0,09$ & 0,11 & 0,04 & $-2,3 \%$ & $2,1 \%$ & $0,7 \%$ \\
\hline EP high & 0,44 & 0,18 & 0,08 & $9,7 \%$ & $3,5 \%$ & $1,5 \%$ \\
\hline
\end{tabular}

Panel B: CFP factor.

\begin{tabular}{lrrrrrr}
\hline & \multicolumn{3}{c}{ Sharpe ratio } & \multicolumn{3}{c}{ Treynor ratio } \\
\cline { 5 - 6 } & & \multicolumn{2}{c}{ Value and long-term momentum } & & \\
& LTM low & LTM mid & LTM high & LTM low & LTM mid & LTM high \\
\hline CFP low & $-0,12$ & 0,01 & 0,42 & $-2,4 \%$ & $0,1 \%$ & $9,5 \%$ \\
CFP mid & $-0,06$ & 0,15 & 0,36 & $-1,2 \%$ & $2,9 \%$ & $7,4 \%$ \\
CFP high & 0,15 & 0,18 & 0,42 & $3,2 \%$ & $3,5 \%$ & $9,7 \%$
\end{tabular}

Value and short-term momentum

\begin{tabular}{|c|c|c|c|c|c|c|}
\hline & STM low & STM mid & STM high & STM low & STM mid & STM high \\
\hline CFP low & 0,10 & $-0,10$ & 0,27 & $2,1 \%$ & $-1,9 \%$ & $6,9 \%$ \\
\hline CFP mid & 0,14 & 0,22 & 0,00 & $2,8 \%$ & $4,2 \%$ & $-0,1 \%$ \\
\hline CFP high & 0,19 & 0,25 & 0,32 & $3,7 \%$ & $4,9 \%$ & $7,1 \%$ \\
\hline
\end{tabular}

\begin{tabular}{|c|c|c|c|c|c|c|c|c|c|}
\hline \multicolumn{10}{|c|}{ Value and size } \\
\hline & S low & & $\mathrm{S}$ mid & & S high & S low & & S mid & S high \\
\hline CFP low & & 0,17 & & 0,14 & $-0,02$ & & $4,8 \%$ & $2,8 \%$ & $-0,4 \%$ \\
\hline CFP mid & & 0,35 & & 0,20 & 0,03 & & $8,3 \%$ & $3,7 \%$ & $0,5 \%$ \\
\hline CFP high & & 0,39 & & 0,16 & $-0,02$ & & $8,7 \%$ & $3,2 \%$ & $-0,4 \%$ \\
\hline
\end{tabular}


Panel C: SP factor

\begin{tabular}{lrrrrrr}
\hline & \multicolumn{3}{c}{ Sharpe ratio } & \multicolumn{3}{c}{ Treynor ratio } \\
\cline { 3 - 5 } & & \multicolumn{2}{c}{ Value and long-term momentum } & & \\
& LTM low & LTM mid & LTM high & LTM low & LTM mid & LTM high \\
\hline SP low & $-0,16$ & $-0,02$ & 0,35 & $-3,7 \%$ & $-0,4 \%$ & $8,1 \%$ \\
SP mid & 0,06 & 0,18 & 0,41 & $1,3 \%$ & $3,4 \%$ & $8,2 \%$ \\
SP high & 0,11 & 0,04 & 0,57 & $2,2 \%$ & $0,8 \%$ & $14,3 \%$
\end{tabular}

Value and short-term momentum

\begin{tabular}{|c|c|c|c|c|c|c|}
\hline & STM low & STM mid & STM high & STM low & STM mid & STM high \\
\hline SP low & $-0,08$ & 0,04 & 0,05 & $-1,7 \%$ & $0,9 \%$ & $1,0 \%$ \\
\hline SP mid & 0,28 & 0,28 & 0,04 & $5,5 \%$ & $5,2 \%$ & $0,8 \%$ \\
\hline SP high & 0,18 & 0,11 & 0,21 & $3,5 \%$ & $2,0 \%$ & $4,8 \%$ \\
\hline
\end{tabular}

\begin{tabular}{|c|c|c|c|c|c|c|}
\hline & & & Value and size & & & \\
\hline & S low & S mid & S high & S low & $\mathrm{S}$ mid & S high \\
\hline SP low & 0,03 & $-0,03$ & $-0,12$ & $0,7 \%$ & $-0,6 \%$ & $-2,4 \%$ \\
\hline SP mid & 0,17 & 0,18 & 0,20 & $3,7 \%$ & $3,4 \%$ & $3,6 \%$ \\
\hline SP high & 0,40 & 0,26 & $-0,05$ & $9,9 \%$ & $5,0 \%$ & $-1,0 \%$ \\
\hline
\end{tabular}

Panel D: BVMV factor.

\begin{tabular}{lrrrrrr}
\hline & \multicolumn{3}{c}{ Sharpe ratio } & \multicolumn{2}{c}{ Treynor ratio } \\
\cline { 5 - 6 } & & \multicolumn{2}{c}{ Value and long-term momentum } & & \\
& LTM low & LTM mid & LTM high & LTM low & LTM mid & LTM high \\
\hline BVMV low & $-0,06$ & $-0,07$ & 0,25 & $-1,6 \%$ & $-1,3 \%$ & $5,2 \%$ \\
BVM V mid & 0,06 & 0,22 & 0,31 & $1,3 \%$ & $4,2 \%$ & $6,6 \%$ \\
BVM V high & 0,08 & 0,02 & 0,76 & $1,7 \%$ & $0,4 \%$ & $20,0 \%$
\end{tabular}

Value and short-term momentum

\begin{tabular}{|c|c|c|c|c|c|c|}
\hline & STM low & STM mid & STM high & STM low & STM mid & STM high \\
\hline BVMV low & $-0,10$ & $-0,01$ & $-0,02$ & $-2,1 \%$ & $-0,2 \%$ & $-0,5 \%$ \\
\hline BVMV mid & 0,31 & 0,24 & 0,11 & $6,5 \%$ & $4,5 \%$ & $2,2 \%$ \\
\hline BVMV high & 0,20 & 0,24 & 0,35 & $3,9 \%$ & $4,8 \%$ & $7,7 \%$ \\
\hline
\end{tabular}

Value and size

\begin{tabular}{llrrrrr} 
& S low & \multicolumn{2}{c}{ S mid } & \multicolumn{2}{c}{ S high } & \multicolumn{2}{c}{ S low } & \multicolumn{2}{c}{ S mid } & \multicolumn{2}{c}{ S high } \\
\hline BVMV low & 0,20 & $-0,14$ & 0,01 & $5,5 \%$ & $-2,8 \%$ & $0,2 \%$ \\
BVM V mid & 0,30 & 0,25 & 0,04 & $6,8 \%$ & $4,8 \%$ & $0,8 \%$ \\
BVMV high & 0,24 & 0,28 & 0,10 & $5,3 \%$ & $5,5 \%$ & $2,0 \%$ \\
\hline
\end{tabular}


Table 10. Performance of value portfolios vs size and momentum - local indices

The table 10. presents two popular performance measures (Sharpe ratio and Treynor ratio) of portfolios sorted on combination of two factors. All the measures are presented on annualised basis and computed based on log-returns according to formulas described in the manuscript. Portfolios are sorted according to value factors (earnings yield ("EP"), cash flow yield ("CFP”), sales to price ratio ("SP”) and book value to market value ratio ("BVMV") and market conditions (total market capitalization ("S"), long-term momentum ("LTM") and short-term momentum ("STM")). The market portfolio is computed as the capitalization weighted-average of country portfolio returns. As the proxy for the money market returns, I use 1month bids for BBA Libor USD. The data source is Bloomberg and the calculations are based on listings from 66 countries during a period 01/31/2000-11/29/2013 (12/31/2000-11/29/2013). The local indices are used. The panels A, B, C and D exhibit results of analysis of the EP, CFP, SP and BVMV factors.

Panel A: EP factor.

\begin{tabular}{lrrrrrr}
\hline & \multicolumn{3}{c}{ Sharpe ratio } & \multicolumn{3}{c}{ Treynor ratio } \\
\cline { 3 - 5 } & & \multicolumn{2}{c}{ Value and long-term momentum } & & \\
& LTM low & LTM mid & LTM high & LTM low & LTM mid & LTM high \\
\hline EP low & $-0,09$ & $-0,03$ & 0,13 & $-1,9 \%$ & $-0,6 \%$ & $2,8 \%$ \\
EP mid & $-0,07$ & 0,08 & 0,20 & $-1,4 \%$ & $1,5 \%$ & $4,2 \%$ \\
EP high & 0,13 & 0,20 & 0,44 & $2,6 \%$ & $4,0 \%$ & $10,7 \%$
\end{tabular}

Value and short-term momentum

\begin{tabular}{|c|c|c|c|c|c|c|}
\hline & STM low & STM mid & STM high & STM low & STM mid & STM high \\
\hline EP low & $-0,04$ & 0,11 & 0,25 & $-0,9 \%$ & $2,1 \%$ & $6,8 \%$ \\
\hline EP mid & 0,14 & 0,05 & 0,07 & $2,9 \%$ & $0,9 \%$ & $1,5 \%$ \\
\hline EP high & 0,17 & 0,14 & 0,41 & $3,2 \%$ & $2,8 \%$ & $9,6 \%$ \\
\hline
\end{tabular}

\begin{tabular}{|c|c|c|c|c|c|c|c|c|}
\hline \multicolumn{9}{|c|}{ Value and size } \\
\hline & S low & & S mid & & S high & S low & $\mathrm{S}$ mid & S high \\
\hline EP low & & 0,06 & & 0,10 & $-0,05$ & $1,4 \%$ & $2,2 \%$ & $-0,9 \%$ \\
\hline EP mid & & 0,09 & & 0,03 & 0,09 & $2,2 \%$ & $0,6 \%$ & $1,6 \%$ \\
\hline EP high & & 0,45 & & 0,21 & $-0,10$ & $10,2 \%$ & $4,0 \%$ & $-1,9 \%$ \\
\hline
\end{tabular}

Panel B: CFP factor.

\begin{tabular}{lrrrrrr}
\hline & \multicolumn{3}{c}{ Sharpe ratio } & \multicolumn{3}{c}{ Treynor ratio } \\
\cline { 3 - 5 } & Value and long-term momentum & & \\
& LTM low & LTM mid & LTM high & LTM low & LTM mid & LTM high \\
\hline CFP low & $-0,13$ & $-0,13$ & 0,44 & $-2,7 \%$ & $-2,5 \%$ & $10,3 \%$ \\
CFP mid & 0,03 & 0,14 & 0,32 & $0,7 \%$ & $2,6 \%$ & $6,7 \%$ \\
CFP high & 0,10 & 0,12 & 0,52 & $2,1 \%$ & $2,4 \%$ & $12,0 \%$
\end{tabular}

Value and short-term momentum

\begin{tabular}{|c|c|c|c|c|c|c|}
\hline & STM low & STM mid & STM high & STM low & STM mid & STM high \\
\hline CFP low & 0,02 & $-0,06$ & 0,10 & $0,4 \%$ & $-1,2 \%$ & $2,4 \%$ \\
\hline CFP mid & 0,19 & 0,06 & 0,25 & $4,0 \%$ & $1,1 \%$ & $5,3 \%$ \\
\hline CFP high & 0,20 & 0,26 & 0,30 & $3,9 \%$ & $5,3 \%$ & $6,6 \%$ \\
\hline
\end{tabular}

\begin{tabular}{|c|c|c|c|c|c|c|c|c|}
\hline \multicolumn{9}{|c|}{ Value and size } \\
\hline & S low & & S mid & & S high & S low & $\mathrm{S}$ mid & S high \\
\hline CFP low & & 0,11 & & $-0,04$ & 0,16 & $2,7 \%$ & $-0,8 \%$ & $3,1 \%$ \\
\hline CFP mid & & 0,25 & & 0,17 & 0,08 & $5,7 \%$ & $3,3 \%$ & $1,4 \%$ \\
\hline CFP high & & 0,48 & & 0,22 & 0,02 & $10,7 \%$ & $4,3 \%$ & $0,4 \%$ \\
\hline
\end{tabular}


Panel C: SP factor

\begin{tabular}{lrrrrrr}
\hline & \multicolumn{3}{c}{ Sharpe ratio } & \multicolumn{3}{c}{ Treynor ratio } \\
\cline { 3 - 5 } & \multicolumn{2}{c}{ Value and long-term momentum } & & \\
& LTM low & LTM mid & LTM high & LTM low & LTM mid & LTM high \\
\hline SP low & $-0,13$ & $-0,04$ & 0,46 & $-3,3 \%$ & $-0,7 \%$ & $10,4 \%$ \\
SP mid & 0,12 & 0,12 & 0,20 & $2,5 \%$ & $2,4 \%$ & $4,2 \%$ \\
SP high & 0,00 & 0,17 & 0,56 & $0,1 \%$ & $3,4 \%$ & $14,1 \%$
\end{tabular}

Value and short-term momentum

\begin{tabular}{|c|c|c|c|c|c|c|}
\hline & STM low & STM mid & STM high & STM low & STM mid & STM high \\
\hline SP low & 0,12 & 0,06 & $-0,03$ & $2,6 \%$ & $1,2 \%$ & $-0,6 \%$ \\
\hline SP mid & 0,22 & 0,06 & 0,02 & $4,3 \%$ & $1,1 \%$ & $0,4 \%$ \\
\hline SP high & 0,18 & 0,13 & 0,41 & $3,5 \%$ & $2,5 \%$ & $8,9 \%$ \\
\hline
\end{tabular}

\begin{tabular}{lllrrrr} 
& \multicolumn{9}{c}{ Value and size } & \multicolumn{2}{c}{ S mid } & \multicolumn{2}{c}{ S high } \\
& S low & & S mid & \multicolumn{2}{c}{ S high } & \multicolumn{2}{c}{ S low } & S & \\
\hline SP low & 0,11 & 0,07 & 0,05 & $2,8 \%$ & $1,5 \%$ & $0,9 \%$ \\
SP mid & 0,16 & 0,15 & 0,11 & $3,5 \%$ & $2,9 \%$ & $2,0 \%$ \\
SP high & 0,44 & 0,17 & $-0,07$ & $10,1 \%$ & $3,3 \%$ & $-1,2 \%$ \\
\hline
\end{tabular}

Panel D: BVMV factor.

\begin{tabular}{lrrrrrr}
\hline & \multicolumn{3}{c}{ Sharpe ratio } & \multicolumn{3}{c}{ Treynor ratio } \\
\cline { 5 - 6 } & & \multicolumn{2}{c}{ Value and long-term momentum } & & \\
& LTM low & LTM mid & LTM high & LTM low & LTM mid & LTM high \\
\hline BVM V low & $-0,01$ & $-0,07$ & 0,27 & $-0,3 \%$ & $-1,3 \%$ & $5,8 \%$ \\
BVM V mid & 0,04 & 0,26 & 0,30 & $0,9 \%$ & $5,0 \%$ & $6,4 \%$ \\
BVM V high & 0,12 & 0,13 & 0,59 & $2,5 \%$ & $2,5 \%$ & $15,4 \%$
\end{tabular}

Value and short-term momentum

\begin{tabular}{|c|c|c|c|c|c|c|}
\hline & STM low & STM mid & STM high & STM low & STM mid & STM high \\
\hline BVMV low & 0,03 & $-0,08$ & $-0,08$ & $0,6 \%$ & $-1,6 \%$ & $-1,7 \%$ \\
\hline BVMV mid & 0,40 & 0,14 & 0,15 & $8,0 \%$ & $2,7 \%$ & $3,0 \%$ \\
\hline BVMV high & 0,22 & 0,23 & 0,24 & $4,3 \%$ & $4,7 \%$ & $5,4 \%$ \\
\hline
\end{tabular}

Value and size

\begin{tabular}{|c|c|c|c|c|c|c|}
\hline & S low & $\mathrm{S}$ mid & S high & S low & S mid & S high \\
\hline BVMV low & 0,19 & $-0,07$ & 0,01 & $5,3 \%$ & $-1,3 \%$ & $0,2 \%$ \\
\hline BVMV mid & 0,28 & 0,22 & 0,08 & $6,3 \%$ & $4,2 \%$ & $1,4 \%$ \\
\hline BVMV high & 0,32 & 0,18 & 0,07 & $6,9 \%$ & $3,6 \%$ & $1,3 \%$ \\
\hline
\end{tabular}


Table 11. Performance of market-neutral portfolios vs size and momentum - MSCI indices

The table 11. exhibits return characteristics of market-neutral factor mimicking portfolios in the two-dimensional approach. Portfolios are created based combinations of two of value factors (earnings yield ("EP”), cash flow yield (“CFP”), sales to price ratio ("SP") and book value to market value ratio ("BVMV") and market conditions (total market capitalization ("S"), long-term momentum ("LTM") and short-term momentum ("STM")).. "Return" is the average annual geometric rate of return and "volatility" is an annual standard deviation of log-returns. HML, SMB, $\alpha$ and $\beta$ are model parameters computed in each case according to the model' specification. I use log-returns in all computations. Data on HML and SML factors comes from Kenneth's R. French website. The market portfolio is computed as the capitalization weighted average of country portfolio returns. As the proxy for the money market returns, I use 1-month bids for BBA Libor USD. Numbers in brackets below denote the statistical significance (t-stat). The data source is Bloomberg and the calculations are based on listings from 66 countries during a period 04/30/200011/29/2013. The MSCI indices are used. The panels A, B, C and D exhibit results of analysis of the EP, CFP, SP and BVMV factors.

Panel A: EP factor.

\begin{tabular}{lccccccrrrr}
\hline & \multicolumn{2}{c}{ Zero model } & \multicolumn{2}{c}{ Market model } & \multicolumn{2}{c}{ CAPM } & \multicolumn{4}{c}{ Fama-French three factor model } \\
& Return & Volatility & \multicolumn{1}{c}{$\beta$} & $\alpha$ & \multicolumn{1}{c}{$\beta$} & $\alpha$ & HML & \multicolumn{1}{c}{ SMB } & \multicolumn{1}{c}{$\beta$} & $\alpha$ \\
\hline EP+LTM & $1,49 \%$ & $5,69 \%$ & $-0,02$ & $1,50 \%$ & $-0,02$ & $1,31 \%$ & $-0,29$ & $-0,19$ & 0,08 & $1,50 \%$ \\
& $(3,34)$ & & $(-0,23)$ & $(3,33)$ & $(-0,18)$ & $(2,91)$ & $(-2,27)$ & $(-1,13)$ & $(0,80)$ & $(3,33)$ \\
EP+STM & $0,64 \%$ & $6,05 \%$ & $-0,04$ & $0,65 \%$ & $-0,03$ & $0,45 \%$ & $-0,33$ & 0,07 & 0,02 & $0,55 \%$ \\
& $(1,35)$ & & $(-0,45)$ & $(1,36)$ & $(-0,37)$ & $(0,95)$ & $(-2,44)$ & $(0,35)$ & $(0,17)$ & $(1,14)$ \\
EP+S & $1,04 \%$ & $4,22 \%$ & $-0,09$ & $1,06 \%$ & $-0,09$ & $0,85 \%$ & 0,16 & 0,20 & $-0,16$ & $0,70 \%$ \\
& $(3,14)$ & & $(-1,40)$ & $(3,20)$ & $(-1,37)$ & $(2,59)$ & $(1,72)$ & $(1,55)$ & $(-2,23)$ & $(2,11)$ \\
\hline
\end{tabular}

Panel B: CFP factor.

\begin{tabular}{lccccccrrrr}
\hline & \multicolumn{2}{c}{ Zero model } & \multicolumn{2}{c}{ Market model } & \multicolumn{3}{c}{ CAPM } & \multicolumn{4}{c}{ Fama-French three factor model } \\
& Return & Volatility & \multicolumn{1}{c}{$\beta$} & $\alpha$ & \multicolumn{1}{c}{$\beta$} & $\alpha$ & HML & \multicolumn{1}{c}{ SMB } & \multicolumn{1}{c}{$\beta$} & $\alpha$ \\
\hline CP+LTM & $1,06 \%$ & $5,34 \%$ & $-0,17$ & $1,09 \%$ & $-0,17$ & $0,87 \%$ & $-0,35$ & 0,06 & $-0,11$ & $0,98 \%$ \\
& $(2,53)$ & & $(-2,08)$ & $(2,62)$ & $(-2,03)$ & $(2,10)$ & $(-2,98)$ & $(0,37)$ & $(-1,24)$ & $(2,35)$ \\
CP+STM & $0,38 \%$ & $5,62 \%$ & $-0,14$ & $0,41 \%$ & $-0,14$ & $0,20 \%$ & $-0,18$ & 0,19 & $-0,14$ & $0,18 \%$ \\
& $(0,87)$ & & $(-1,64)$ & $(0,93)$ & $(-1,60)$ & $(0,45)$ & $(-1,41)$ & $(1,10)$ & $(-1,47)$ & $(0,39)$ \\
CP+S & $0,83 \%$ & $4,42 \%$ & $-0,24$ & $0,87 \%$ & $-0,23$ & $0,64 \%$ & 0,16 & 0,22 & $-0,30$ & $0,48 \%$ \\
& $(2,39)$ & & $(-3,57)$ & $(2,60)$ & $(-3,56)$ & $(1,92)$ & $(1,69)$ & $(1,69)$ & $(-4,28)$ & $(1,43)$ \\
\hline
\end{tabular}

Panel C: SP factor.

\begin{tabular}{lccccccrrrr}
\hline & \multicolumn{1}{c}{ Zero model } & \multicolumn{2}{c}{ Market model } & \multicolumn{2}{c}{ CAPM } & \multicolumn{4}{c}{ Fama-French three factor model } \\
& Return & Volatility & \multicolumn{1}{c}{$\beta$} & \multicolumn{1}{c}{$\alpha$} & \multicolumn{1}{c}{$\beta$} & \multicolumn{1}{c}{$\alpha$} & \multicolumn{1}{c}{ HML } & \multicolumn{1}{c}{ SMB } & \multicolumn{1}{c}{$\beta$} & $\alpha$ \\
\hline SP+LTM & $1,30 \%$ & $5,82 \%$ & $-0,07$ & $1,32 \%$ & $-0,06$ & $1,12 \%$ & $-0,25$ & $-0,22$ & 0,03 & $1,31 \%$ \\
& $(2,85)$ & & $(-0,76)$ & $(2,87)$ & $(-0,71)$ & $(2,44)$ & $(-1,89)$ & $(-1,26)$ & $(0,26)$ & $(2,84)$ \\
SP+STM & $0,58 \%$ & $5,31 \%$ & $-0,05$ & $0,59 \%$ & $-0,04$ & $0,40 \%$ & $-0,03$ & $-0,11$ & $-0,02$ & $0,46 \%$ \\
& $(1,40)$ & & $(-0,55)$ & $(1,42)$ & $(-0,53)$ & $(0,95)$ & $(-0,21)$ & $(-0,69)$ & $(-0,20)$ & $(1,07)$ \\
SP+S & $0,99 \%$ & $5,29 \%$ & $-0,26$ & $1,04 \%$ & $-0,25$ & $0,80 \%$ & 0,35 & 0,07 & $-0,33$ & $0,64 \%$ \\
& $(2,39)$ & & $(-3,22)$ & $(2,57)$ & $(-3,21)$ & $(2,00)$ & $(3,09)$ & $(0,45)$ & $(-3,94)$ & $(1,60)$ \\
\hline
\end{tabular}

Panel D: BVMV factor.

\begin{tabular}{lccrrrrrrrr}
\hline & \multicolumn{2}{c}{ Zero model } & \multicolumn{2}{c}{ Market model } & \multicolumn{2}{c}{ CAPM } & \multicolumn{4}{c}{ Fama-French three factor model } \\
& Return & Volatility & \multicolumn{1}{c}{$\beta$} & \multicolumn{1}{c}{$\alpha$} & \multicolumn{1}{c}{$\beta$} & \multicolumn{1}{c}{$\alpha$} & \multicolumn{1}{c}{ HML } & \multicolumn{1}{c}{ SMB } & \multicolumn{1}{c}{$\beta$} & $\alpha$ \\
\hline BVMV +LTM & $1,36 \%$ & $9,11 \%$ & $-0,19$ & $1,39 \%$ & $-0,18$ & $1,17 \%$ & $-0,34$ & $-0,20$ & $-0,08$ & $1,39 \%$ \\
& $(1,90)$ & & $-1,33)$ & $(1,95)$ & $(-1,30)$ & $(1,64)$ & $(-1,63)$ & $(-0,71)$ & $(-0,53)$ & $(1,91)$ \\
BVM V+STM & $0,85 \%$ & $5,40 \%$ & $-0,15$ & $0,88 \%$ & $-0,15$ & $0,66 \%$ & 0,05 & 0,13 & $-0,19$ & $0,58 \%$ \\
& $(2,00)$ & & $(-1,86)$ & $(2,08)$ & $(-1,89)$ & $(1,58)$ & $(0,40)$ & $(0,79)$ & $(-2,08)$ & $(1,36)$ \\
BVM V+S & $0,53 \%$ & $4,75 \%$ & $-0,13$ & $0,56 \%$ & $-0,13$ & $0,35 \%$ & 0,46 & 0,31 & $-0,27$ & $0,03 \%$ \\
& $(1,43)$ & & $(-1,79)$ & $(1,50)$ & $(-1,75)$ & $(0,94)$ & $(4,65)$ & $(2,31)$ & $(-3,69)$ & $(0,08)$ \\
\hline
\end{tabular}


Table 12. Performance of market-neutral portfolios vs size and momentum - local indices

The table 12. exhibits return characteristics of market-neutral factor mimicking portfolios in the two-dimensional approach. Portfolios are created based combinations of two of value factors (earnings yield ("EP"), cash flow yield ("CFP”), sales to price ratio ("SP") and book value to market value ratio ("BVMV") and market conditions (total market capitalization ("S"), long-term momentum ("LTM") and short-term momentum ("STM")). "Return" is the average annual geometric rate of return and "volatility" is an annual standard deviation of log-returns. HML, SMB, $\alpha$ and $\beta$ are model parameters computed in each case according to the model' specification. I use log-returns in all computations. Data on HML and SML factors comes from Kenneth's R. French website. The market portfolio is computed as the capitalization weighted average of country portfolio returns. As the proxy for the money market returns, I use 1-month bids for BBA Libor USD. Numbers in brackets below denote the statistical significance (t-stat). The data source is Bloomberg and the calculations are based on listings from 66 countries during a period 01/31/200011/29/2013 (12/31/2000-11/29/2013). The local indices are used. The panels A, B, C and D exhibit results of analysis of the EP, CFP, SP and BVMV factors.

Panel A: EP factor.

\begin{tabular}{lccrcrrrrrr}
\hline & \multicolumn{2}{c}{ Zero model } & \multicolumn{2}{c}{ Market model } & \multicolumn{2}{c}{ CAPM } & \multicolumn{4}{c}{ Fama-French three factor model } \\
& Return & Volatility & \multicolumn{1}{c}{$\beta$} & $\alpha$ & \multicolumn{1}{c}{$\beta$} & $\alpha$ & HML & \multicolumn{1}{c}{ SMB } & \multicolumn{1}{c}{$\beta$} & $\alpha$ \\
\hline EP +LTM & $1,02 \%$ & $6,09 \%$ & $-0,13$ & $1,04 \%$ & $-0,13$ & $0,83 \%$ & $-0,34$ & $-0,02$ & $-0,06$ & $0,97 \%$ \\
& $(2,13)$ & & $(-1,44)$ & $(2,19)$ & $(-1,41)$ & $(1,74)$ & $(-2,48)$ & $(-0,13)$ & $(-0,60)$ & $(2,02)$ \\
EP+STM & $0,95 \%$ & $5,55 \%$ & 0,00 & $0,95 \%$ & 0,00 & $0,77 \%$ & 0,03 & 0,23 & $-0,04$ & $0,65 \%$ \\
& $(2,18)$ & & $(-0,03)$ & $(2,18)$ & $(0,04)$ & $(1,75)$ & $(0,23)$ & $(1,36)$ & $(-0,47)$ & $(1,44)$ \\
EP+S & $1,19 \%$ & $4,39 \%$ & 0,07 & $1,18 \%$ & 0,07 & $1,00 \%$ & 0,23 & $-0,03$ & 0,03 & $0,93 \%$ \\
& $(3,45)$ & & $(0,99)$ & $(3,41)$ & $(1,05)$ & $(2,91)$ & $(2,29)$ & $(-0,20)$ & $(0,42)$ & $(2,67)$ \\
\hline
\end{tabular}

Panel B: CFP factor.

\begin{tabular}{lccccccrrrr}
\hline & \multicolumn{2}{c}{ Zero model } & \multicolumn{2}{c}{ Market model } & \multicolumn{2}{c}{ CAPM } & \multicolumn{3}{c}{ Fama-French three factor model } \\
& Return & Volatility & \multicolumn{1}{c}{$\beta$} & \multicolumn{1}{c}{$\alpha$} & \multicolumn{1}{c}{$\beta$} & \multicolumn{1}{c}{$\alpha$} & HML & \multicolumn{1}{c}{ SMB } & \multicolumn{1}{c}{$\beta$} & $\alpha$ \\
\hline CFP + LTM & $1,16 \%$ & $5,48 \%$ & $-0,28$ & $1,22 \%$ & $-0,28$ & $1,01 \%$ & $-0,25$ & $-0,02$ & $-0,22$ & $1,08 \%$ \\
& $(2,63)$ & & $(-3,37)$ & $(2,86)$ & $(-3,37)$ & $(2,37)$ & $(-1,68)$ & $(-0,11)$ & $(-2,33)$ & $(2,49)$ \\
CFP+STM & $0,46 \%$ & $5,68 \%$ & $-0,20$ & $0,51 \%$ & $-0,20$ & $0,31 \%$ & 0,26 & $-0,03$ & $-0,25$ & $0,26 \%$ \\
& $(1,01)$ & & $(-2,26)$ & $(1,13)$ & $(-2,25)$ & $(0,68)$ & $(1,66)$ & $(-0,17)$ & $(-2,57)$ & $(0,57)$ \\
CFP+S & $0,65 \%$ & $4,33 \%$ & $-0,19$ & $0,69 \%$ & $-0,18$ & $0,49 \%$ & 0,49 & 0,05 & $-0,31$ & $0,35 \%$ \\
& $(1,86)$ & & $(-2,84)$ & $(2,03)$ & $(-2,78)$ & $(1,45)$ & $(4,38)$ & $(0,39)$ & $(-4,39)$ & $(1,08)$ \\
\hline
\end{tabular}

Panel C: SP factor.

\begin{tabular}{|c|c|c|c|c|c|c|c|c|c|c|}
\hline & \multicolumn{2}{|c|}{ Zero model } & \multicolumn{2}{|c|}{ Market model } & \multicolumn{2}{|c|}{$\overline{\text { CAPM }}$} & \multicolumn{4}{|c|}{ Fama-French three factor model } \\
\hline & Return & Volatility & $\beta$ & $\alpha$ & $\beta$ & $\alpha$ & HML & SMB & $\beta$ & $\alpha$ \\
\hline \multirow[t]{2}{*}{$\mathrm{SP}+\mathrm{LTM}$} & $1,17 \%$ & $6,46 \%$ & $-0,13$ & $1,19 \%$ & $-0,12$ & $0,98 \%$ & $-0,23$ & $-0,19$ & $-0,04$ & $1,15 \%$ \\
\hline & $(2,30)$ & & $(-1,27)$ & $(2,35)$ & $(-1,21)$ & $(1,93)$ & $(-1,58)$ & $(-0,94)$ & $(-0,40)$ & $(2,24)$ \\
\hline \multirow[t]{2}{*}{$\mathrm{SP}+\mathrm{STM}$} & $0,65 \%$ & $5,50 \%$ & 0,09 & $0,64 \%$ & 0,09 & $0,47 \%$ & 0,04 & 0,08 & 0,07 & $0,41 \%$ \\
\hline & $(1,51)$ & & $(1,04)$ & $(1,47)$ & $(1,10)$ & $(1,08)$ & $(0,31)$ & $(0,50)$ & $(0,75)$ & $(0,93)$ \\
\hline \multirow[t]{2}{*}{$\mathrm{SP}+\mathrm{S}$} & $0,91 \%$ & $4,61 \%$ & $-0,08$ & $0,93 \%$ & $-0,08$ & $0,73 \%$ & 0,28 & 0,15 & $-0,16$ & $0,55 \%$ \\
\hline & $(2,52)$ & & $(-1,15)$ & $(2,56)$ & $(-1,09)$ & $(2,01)$ & $(2,74)$ & $(1,06)$ & $(-2,06)$ & $(1,53)$ \\
\hline
\end{tabular}

Panel D: BVMV factor.

\begin{tabular}{lccrrrrrrrr}
\hline & \multicolumn{2}{c}{ Zero model } & \multicolumn{2}{c}{ Market model } & \multicolumn{2}{c}{ CAPM } & \multicolumn{4}{c}{ Fama-French three factor model } \\
& Return & Volatility & \multicolumn{1}{c}{$\beta$} & \multicolumn{1}{c}{$\alpha$} & \multicolumn{1}{c}{$\beta$} & \multicolumn{1}{c}{$\alpha$} & \multicolumn{1}{c}{ HML } & \multicolumn{1}{c}{ SMB } & \multicolumn{1}{l}{$\beta$} & \multicolumn{1}{c}{$\alpha$} \\
\hline BVM V +LTM & $1,10 \%$ & $7,85 \%$ & $-0,11$ & $1,12 \%$ & $-0,10$ & $0,91 \%$ & $-0,38$ & $-0,14$ & $-0,01$ & $1,12 \%$ \\
& $(1,79)$ & & $(-0,90)$ & $(1,81)$ & $(-0,87)$ & $(1,48)$ & $(-2,14)$ & $(-0,59)$ & $(-0,05)$ & $(1,80)$ \\
BVM V+STM & $0,46 \%$ & $5,54 \%$ & $-0,03$ & $0,46 \%$ & $-0,03$ & $0,27 \%$ & 0,05 & 0,11 & $-0,06$ & $0,20 \%$ \\
& $(1,05)$ & & $(-0,32)$ & $(1,06)$ & $(-0,32)$ & $(0,62)$ & $(0,43)$ & $(0,66)$ & $(-0,62)$ & $(0,44)$ \\
BVM V+S & $0,73 \%$ & $4,46 \%$ & $-0,05$ & $0,74 \%$ & $-0,05$ & $0,54 \%$ & 0,34 & 0,36 & $-0,18$ & $0,25 \%$ \\
& $(2,08)$ & & $(-0,77)$ & $(2,11)$ & $(-0,73)$ & $(1,55)$ & $(3,53)$ & $(2,79)$ & $(-2,54)$ & $(0,73)$ \\
\hline
\end{tabular}


Table 13. Value factors and market tensions - absolute changes

The regression models estimated for log-returns to value-factors' zero-cost market neutral mimicking portfolios are based on monthly and quaterly observations. The log-returns are regressed against absolute changes in AAA credit spread ("AAA"), BAA credit spread ("BAA"), volatility index ("VIX"), JPM Global PMI Manufacturing ("PMI") and TED spread ("TED"). The first number in each cell is the OLS estimation of the model's parameter. A number in brackets is the t-statistics estimated in parametrical way. The data come from Bloomberg. Panel A exhibits computations based on monthly data and panel B refers to quarterly data.

Panel A: monthly data.

\begin{tabular}{ccccccccccc}
\hline & \multicolumn{2}{c}{ AAA } & \multicolumn{2}{c}{ BAA } & \multicolumn{2}{c}{ VIX } & \multicolumn{3}{c}{ PMI } & \multicolumn{2}{c}{ TED } \\
& $\beta$ & $\alpha$ & $\beta$ & $\alpha$ & $\beta$ & $\alpha$ & $\beta$ & $\alpha$ & $\beta$ & $\alpha$ \\
\hline BVMV & $-0,020$ & 0,006 & $-0,004$ & 0,006 & $-0,094$ & 0,006 & 0,489 & 0,006 & $-1,404$ & 0,006 \\
& $(-2,25)$ & $(2,63)$ & $(-0,34)$ & $(2,59)$ & $(-1,89)$ & $(2,59)$ & $(2,81)$ & $(2,68)$ & $(-1,58)$ & $(2,57)$ \\
\hline SP & $-0,023$ & 0,003 & $-0,017$ & 0,003 & $-0,195$ & 0,003 & 0,424 & 0,003 & $-1,552$ & 0,003 \\
& $(-2,33)$ & $(1,20)$ & $(-1,25)$ & $(1,19)$ & $(-3,68)$ & $(1,18)$ & $(2,19)$ & $(1,22)$ & $(-1,58)$ & $(1,15)$ \\
\hline CFP & 0,002 & 0,003 & 0,011 & 0,003 & 0,022 & 0,003 & 0,067 & 0,003 & 0,166 & 0,003 \\
& $(0,26)$ & $(1,63)$ & $(1,13)$ & $(1,63)$ & $(0,55)$ & $(1,64)$ & $(0,46)$ & $(1,63)$ & $(0,23)$ & $(1,63)$ \\
\hline EP & $-0,027$ & 0,006 & $-0,016$ & 0,006 & $-0,089$ & 0,006 & 0,540 & 0,006 & $-1,385$ & 0,006 \\
& $(-3,29)$ & $(2,73)$ & $(-1,43)$ & $(2,67)$ & $(-1,92)$ & $(2,64)$ & $(3,36)$ & $(2,77)$ & $(-1,67)$ & $(2,62)$ \\
\hline
\end{tabular}

Panel B: quarterly data.

\begin{tabular}{ccccccccccc}
\hline & \multicolumn{2}{c}{ AAA } & \multicolumn{2}{c}{ BAA } & \multicolumn{2}{c}{ VIX } & \multicolumn{2}{c}{ PMI } & \multicolumn{3}{c}{ TED } \\
& $\beta$ & $\alpha$ & $\beta$ & $\alpha$ & $\beta$ & $\alpha$ & $\beta$ & $\alpha$ & $\beta$ & $\alpha$ \\
\hline BVMV & $-0,049$ & 0,018 & $-0,090$ & 0,018 & $-0,291$ & 0,017 & 0,645 & 0,018 & $-4,844$ & 0,017 \\
& $(-3,66)$ & $(2,53)$ & $(-3,25)$ & $(2,51)$ & $(-3,05)$ & $(2,36)$ & $(2,58)$ & $(2,42)$ & $(-2,20)$ & $(2,22)$ \\
\hline SP & $-0,046$ & 0,009 & $-0,082$ & 0,009 & $-0,224$ & 0,008 & 0,560 & 0,009 & $-3,927$ & 0,008 \\
& $(-3,14)$ & $(1,17)$ & $(-2,71)$ & $(1,18)$ & $(-2,14)$ & $(1,06)$ & $(2,08)$ & $(1,14)$ & $(-1,66)$ & $(1,00)$ \\
\hline CFP & 0,003 & 0,009 & $-0,020$ & 0,009 & 0,077 & 0,009 & 0,001 & 0,009 & 0,436 & 0,009 \\
& $(0,25)$ & $(1,55)$ & $(-0,90)$ & $(1,57)$ & $(1,01)$ & $(1,59)$ & $(0,01)$ & $(1,55)$ & $(0,25)$ & $(1,56)$ \\
\hline EP & $-0,046$ & 0,017 & $-0,089$ & 0,017 & $-0,238$ & 0,016 & 0,756 & 0,017 & $-3,104$ & 0,016 \\
& $(-3,51)$ & $(2,46)$ & $(-3,30)$ & $(2,47)$ & $(-2,51)$ & $(2,27)$ & $(3,22)$ & $(2,46)$ & $(-1,42)$ & $(2,16)$ \\
\hline
\end{tabular}


Table 14. Value factors and market tensions - logarithmic changes

The regression models estimated for log-returns to value-factors' zero-cost market neutral mimicking portfolios are based on monthly and quarterly observations. The log-returns are regressed against logarithmic percent changes (nepers) in AAA credit spread ("AAA"), BAA credit spread ("BAA"), volatility index ("VIX"), JPM Global PMI Manufacturing ("PMI") and TED spread ("TED"). The first number in each cell is the OLS estimation of the model's parameter. A number in brackets is the t-statistics estimated in parametrical way. The data come from Bloomberg. Panel A exhibits computations based on monthly data and panel B refers to quarterly data.

Panel A: monthly data.

\begin{tabular}{ccccccccccc}
\hline & \multicolumn{2}{c}{ AAA } & \multicolumn{2}{c}{ BAA } & \multicolumn{2}{c}{ VIX } & \multicolumn{3}{c}{ PMI } & \multicolumn{2}{c}{ TED } \\
& $\beta$ & $\alpha$ & $\beta$ & $\alpha$ & $\beta$ & $\alpha$ & $\beta$ & $\alpha$ & $\beta$ & $\alpha$ \\
\hline BVMV & $-0,072$ & 0,006 & $-0,004$ & 0,006 & $-0,094$ & 0,006 & 0,489 & 0,006 & $-1,404$ & 0,006 \\
& $(-2,37)$ & $(2,64)$ & $(-0,34)$ & $(2,59)$ & $(-1,89)$ & $(2,59)$ & $(2,81)$ & $(2,68)$ & $(-1,58)$ & $(2,57)$ \\
\hline SP & $-0,098$ & 0,003 & $-0,017$ & 0,003 & $-0,195$ & 0,003 & 0,424 & 0,003 & $-1,552$ & 0,003 \\
& $(-2,97)$ & $(1,22)$ & $(-1,25)$ & $(1,19)$ & $(-3,68)$ & $(1,18)$ & $(2,19)$ & $(1,22)$ & $(-1,58)$ & $(1,15)$ \\
\hline CFP & $-0,005$ & 0,003 & 0,011 & 0,003 & 0,022 & 0,003 & 0,067 & 0,003 & 0,166 & 0,003 \\
& $(-0,18)$ & $(1,63)$ & $(1,13)$ & $(1,63)$ & $(0,55)$ & $(1,64)$ & $(0,46)$ & $(1,63)$ & $(0,23)$ & $(1,63)$ \\
\hline EP & $-0,096$ & 0,006 & $-0,016$ & 0,006 & $-0,089$ & 0,006 & 0,540 & 0,006 & $-1,385$ & 0,006 \\
& $(-3,46)$ & $(2,74)$ & $(-1,43)$ & $(2,67)$ & $(-1,92)$ & $(2,64)$ & $(3,36)$ & $(2,77)$ & $(-1,67)$ & $(2,62)$ \\
\hline
\end{tabular}

Panel B: quarterly data.

\begin{tabular}{cccccccccccc}
\hline & \multicolumn{2}{c}{ AAA } & \multicolumn{2}{c}{ BAA } & \multicolumn{2}{c}{ VIX } & \multicolumn{2}{c}{ PMI } & \multicolumn{3}{c}{ TED } \\
& $\beta$ & $\alpha$ & $\beta$ & $\alpha$ & $\beta$ & $\alpha$ & $\beta$ & $\alpha$ & $\beta$ & $\alpha$ \\
\hline BVMV & $-0,184$ & 0,018 & $-0,120$ & 0,018 & $-0,070$ & 0,017 & 0,316 & 0,018 & $-0,038$ & 0,016 \\
& $(-3,83)$ & $(2,55)$ & $(-2,61)$ & $(2,43)$ & $(-2,73)$ & $(2,30)$ & $(2,74)$ & $(2,44)$ & $(-2,94)$ & $(2,24)$ \\
\hline SP & $-0,204$ & 0,009 & $-0,124$ & 0,009 & $-0,064$ & 0,008 & 0,252 & 0,009 & $-0,037$ & 0,008 \\
& $(-4,07)$ & $(1,24)$ & $(-2,56)$ & $(1,17)$ & $(-2,34)$ & $(1,04)$ & $(2,01)$ & $(1,13)$ & $(-2,64)$ & $(0,97)$ \\
\hline CFP & $-0,023$ & 0,009 & $-0,041$ & 0,009 & 0,015 & 0,009 & 0,005 & 0,009 & $-0,016$ & 0,009 \\
& $(-0,58)$ & $(1,55)$ & $(-1,14)$ & $(1,58)$ & $(0,76)$ & $(1,58)$ & $(0,05)$ & $(1,55)$ & $(-1,61)$ & $(1,48)$ \\
\hline EP & $-0,175$ & 0,017 & $-0,120$ & 0,017 & $-0,052$ & 0,016 & 0,378 & 0,017 & $-0,025$ & 0,016 \\
& $(-3,73)$ & $(2,49)$ & $(-2,72)$ & $(2,39)$ & $(-2,07)$ & $(2,22)$ & $(3,52)$ & $(2,49)$ & $(-1,89)$ & $(2,16)$ \\
\hline
\end{tabular}




\section{Appemdix 2. Figures.}

Figure 1. Performance of market neutral factor portfolios - MSCI indices.

The figures below depicts the cumulative performance of market-neutral factor mimicking portfolios during the entire research period. Portfolios are created based on earnings yield ("EP"), cash flow yield ("CFP"), sales to price ratio ("SP") and book value to market value ratio ("BVMV"). Standard arithmetic returns are used. The market portfolio is computed as the capitalization weighted average of country portfolio returns. The MSCI indices are used. As the proxy for the money market returns, I use 1-month bids for BBA Libor USD, Euribor and Tibor for USD, EUR and JPY approaches. The data source is Bloomberg and the calculations are based on listings from 66 countries during a period 04/30/2000-11/29/2013. The panels A, B and C exhibit results of computations with all the data converted to USD, EUR and JPY

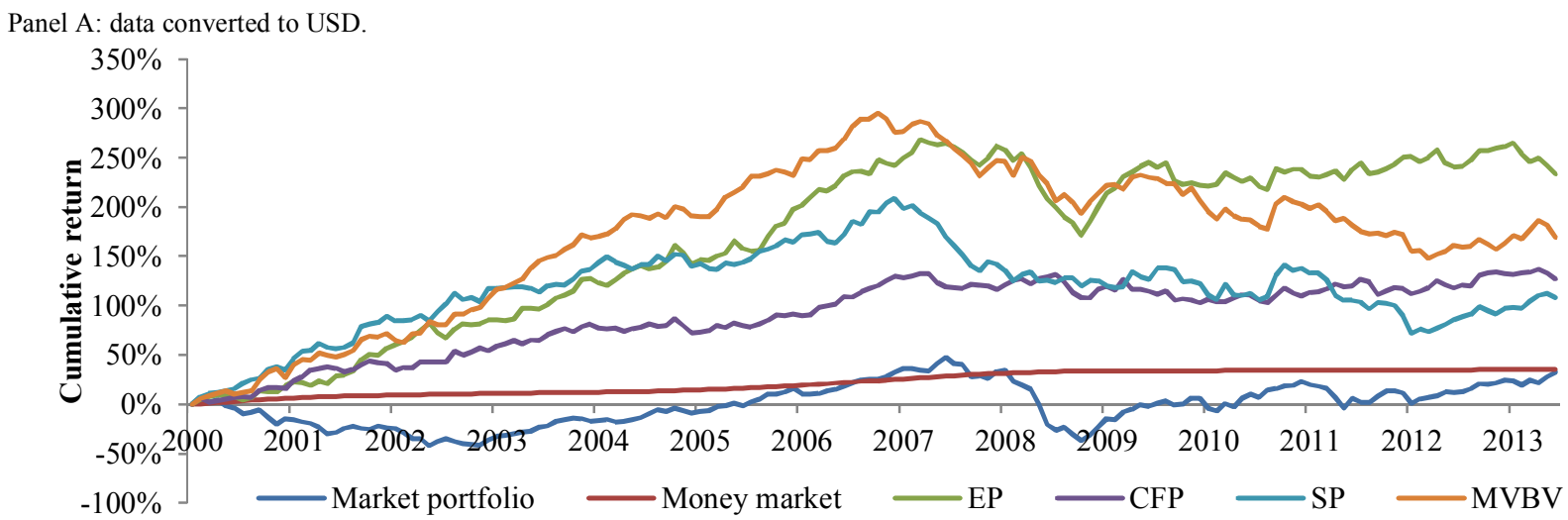

Panel B: data converted to EUR.

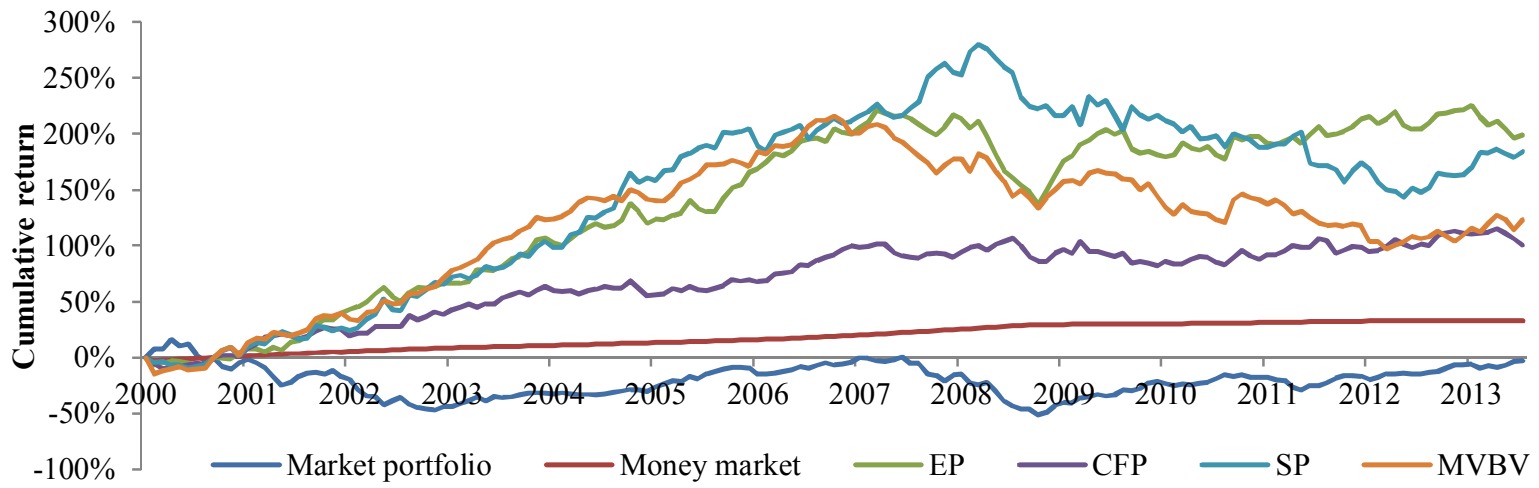

Panel C: data converted to JPY.

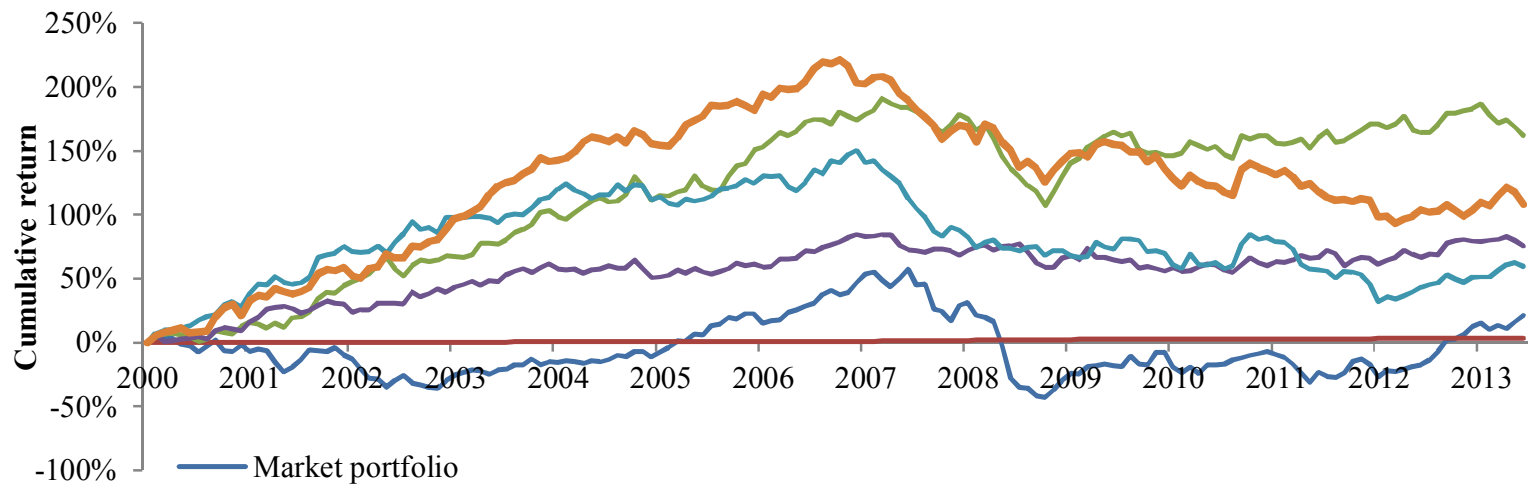


Figure 2. Performance of market neutral factor portfolios - local indices.

The figures below depict the cumulative performance of market-neutral factor mimicking portfolios during the entire research period. Portfolios are created based on earnings yield ("EP"), cash flow yield ("CFP"), sales to price ratio ("SP") and book value to market value ratio ("BVMV"). Standard arithmetic returns are used. The market portfolio is computed as the capitalization weighted average of country portfolio returns. The local indices are used. As the proxy for the money market returns, I use 1-month bids for BBA Libor USD, Euribor and Tibor for USD, EUR and JPY approaches. The data source is Bloomberg and the calculations are based on listings from 66 countries during a period 12/31/2000-11/29/2013. The panels A, B and C exhibit results of computations with all the data converted to USD, EUR and JPY.
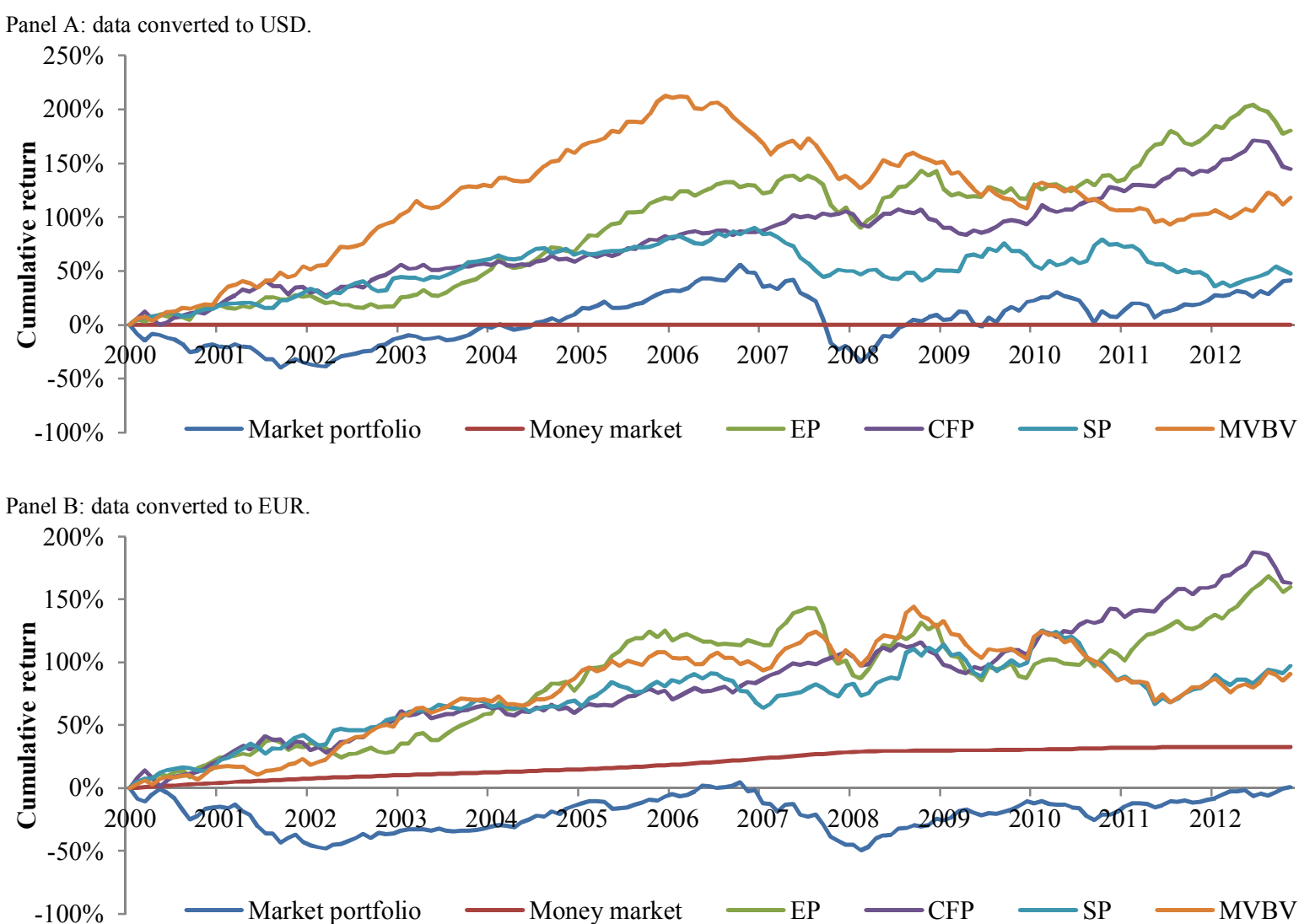

Panel C: data converted to JPY.

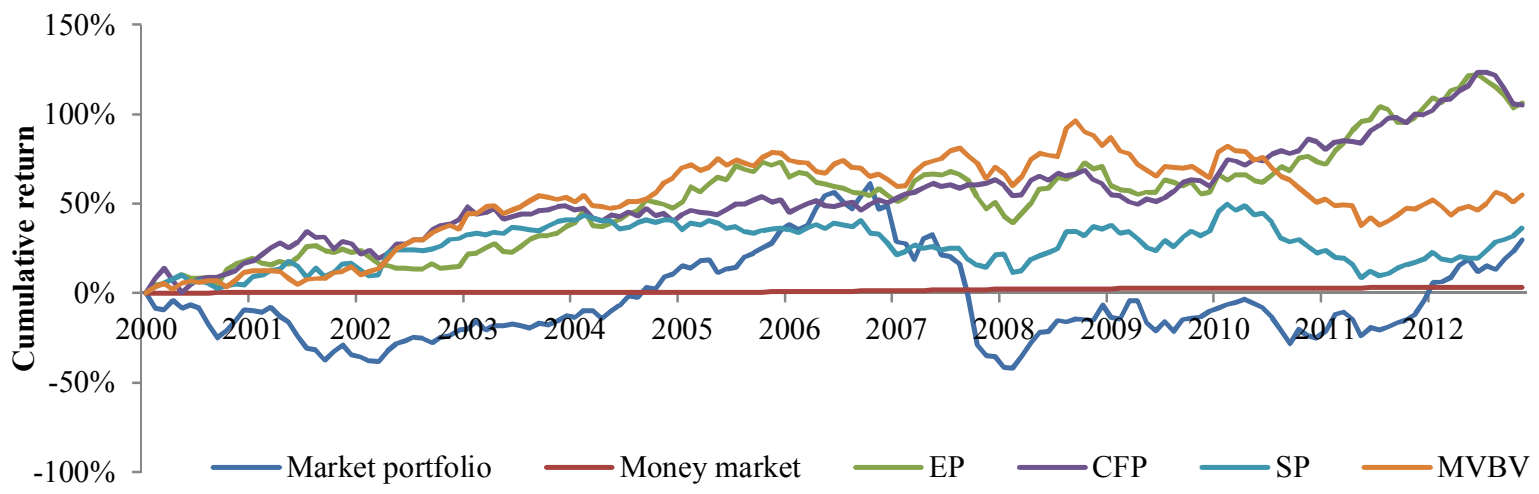




\section{Appendix 3. MSCI country indices.}

The appendix 3. exhibits MSCI indices representing 66 country portfolios used in the research. The timespan refers to the period during which data on all necessary returns and fundamental factor are available, which implies that I sometimes use older data (for example price data for momentum computation). The panel A presents countries with names beginning with A-K and the panel B with names beginning with L-Z.

Panel A: A-K countries.

\begin{tabular}{|c|c|c|c|c|c|c|}
\hline \multirow{2}{*}{ Country } & \multirow{2}{*}{ Name } & \multicolumn{4}{|c|}{ Beginning } & \multirow{2}{*}{ End } \\
\hline & & EP & CFP & SP & BVMV & \\
\hline Argentina & MSCI ARGENTINA & $04 / 30 / 2000$ & $04 / 30 / 2000$ & $04 / 30 / 2000$ & $04 / 30 / 2000$ & $10 / 31 / 2013$ \\
\hline Australia & MSCI AUSTRALIA & $04 / 30 / 2000$ & $04 / 30 / 2000$ & $04 / 30 / 2000$ & $04 / 30 / 2000$ & $10 / 31 / 2013$ \\
\hline Austria & MSCI AUSTRIA & $04 / 30 / 2000$ & $05 / 31 / 2001$ & $04 / 30 / 2000$ & $05 / 31 / 2001$ & $10 / 31 / 2013$ \\
\hline Bahrain & MSCI BAHRAIN & $04 / 30 / 2000$ & $01 / 31 / 2001$ & $04 / 30 / 2000$ & $04 / 30 / 2000$ & $10 / 31 / 2013$ \\
\hline Belgium & MSCI BELGIUM & $04 / 30 / 2000$ & $12 / 31 / 2001$ & $04 / 30 / 2000$ & $12 / 31 / 2001$ & $10 / 31 / 2013$ \\
\hline Brazil & MSCI BRAZIL & $04 / 30 / 2000$ & $06 / 30 / 2003$ & $04 / 30 / 2000$ & $06 / 30 / 2003$ & $10 / 31 / 2013$ \\
\hline Bulgaria & MSCI BULGARIA & $04 / 30 / 2000$ & $04 / 30 / 2000$ & $04 / 30 / 2000$ & $04 / 30 / 2000$ & $10 / 31 / 2013$ \\
\hline Canada & MSCI CANADA & $04 / 30 / 2000$ & $04 / 30 / 2000$ & $04 / 30 / 2000$ & $04 / 30 / 2000$ & $10 / 31 / 2013$ \\
\hline Chile & MSCI CHILE & $03 / 31 / 2008$ & $03 / 31 / 2008$ & $03 / 31 / 2008$ & $03 / 31 / 2008$ & $10 / 31 / 2013$ \\
\hline China & MSCI CHINA & $04 / 30 / 2000$ & $04 / 30 / 2000$ & $04 / 30 / 2000$ & $04 / 30 / 2000$ & $10 / 31 / 2013$ \\
\hline Colombia & MSCI COLOMBIA & $04 / 30 / 2000$ & $04 / 30 / 2000$ & $04 / 30 / 2000$ & $04 / 30 / 2000$ & $10 / 31 / 2013$ \\
\hline Cyprus & GEN. MARKET IND. CSE & $12 / 31 / 2001$ & $04 / 30 / 2000$ & $04 / 30 / 2000$ & $04 / 30 / 2000$ & $10 / 31 / 2013$ \\
\hline Czech Republic & MSCI CZECH REPUBLIC & $04 / 30 / 2000$ & $06 / 30 / 2001$ & $04 / 30 / 2000$ & $06 / 30 / 2001$ & $10 / 31 / 2013$ \\
\hline Denmark & MSCI DENMARK & $04 / 30 / 2000$ & $03 / 31 / 2001$ & $04 / 30 / 2000$ & $03 / 31 / 2001$ & $10 / 31 / 2013$ \\
\hline Egypt & MSCI EGYPT & $04 / 30 / 2000$ & $04 / 30 / 2000$ & $04 / 30 / 2000$ & $11 / 30 / 2000$ & $10 / 31 / 2013$ \\
\hline Estonia & MSCI Estonia & $04 / 30 / 2000$ & $04 / 30 / 2000$ & $04 / 30 / 2000$ & $04 / 30 / 2000$ & $10 / 31 / 2013$ \\
\hline Finland & MSCI FINLAND & $04 / 30 / 2000$ & $04 / 30 / 2000$ & $04 / 30 / 2000$ & $04 / 30 / 2000$ & $10 / 31 / 2013$ \\
\hline France & MSCI FRANCE & $12 / 31 / 2005$ & $04 / 30 / 2000$ & $04 / 30 / 2000$ & $04 / 30 / 2000$ & $10 / 31 / 2013$ \\
\hline Germany & MSCI GERMANY & $04 / 30 / 2000$ & $12 / 31 / 2001$ & $04 / 30 / 2000$ & $12 / 31 / 2001$ & $10 / 31 / 2013$ \\
\hline Great Britain & MSCI UK & $04 / 30 / 2000$ & $02 / 28 / 2006$ & $04 / 30 / 2000$ & $02 / 28 / 2006$ & $10 / 31 / 2013$ \\
\hline Greece & MSCI GREECE & $04 / 30 / 2000$ & $06 / 30 / 2003$ & $04 / 30 / 2000$ & $06 / 30 / 2003$ & $10 / 31 / 2013$ \\
\hline Hong Kong & MSCI HONG KONG & $04 / 30 / 2000$ & $04 / 30 / 2000$ & $04 / 30 / 2000$ & $04 / 30 / 2000$ & $10 / 31 / 2013$ \\
\hline Hungary & MSCI HUNGARY & $06 / 30 / 2008$ & $06 / 30 / 2008$ & $06 / 30 / 2008$ & $06 / 30 / 2008$ & $10 / 31 / 2013$ \\
\hline Iceland & OM X Iceland Ix & $06 / 30 / 2008$ & $06 / 30 / 2008$ & $06 / 30 / 2008$ & $06 / 30 / 2008$ & $10 / 31 / 2013$ \\
\hline India & MSCI INDIA & $06 / 30 / 2008$ & $06 / 30 / 2008$ & $06 / 30 / 2008$ & $06 / 30 / 2008$ & $10 / 31 / 2013$ \\
\hline Indonesia & MSCI INDONESIA & $06 / 30 / 2008$ & $06 / 30 / 2008$ & $06 / 30 / 2008$ & $06 / 30 / 2008$ & $10 / 31 / 2013$ \\
\hline Ireland & MSCI IRELAND & $06 / 30 / 2005$ & $06 / 30 / 2005$ & $06 / 30 / 2005$ & $06 / 30 / 2005$ & $10 / 31 / 2013$ \\
\hline Italy & MSCI ITALY & $06 / 30 / 2009$ & $06 / 30 / 2009$ & $06 / 30 / 2009$ & $06 / 30 / 2009$ & $10 / 31 / 2013$ \\
\hline Japan & MSCI JAPAN & $06 / 30 / 2008$ & $06 / 30 / 2008$ & $06 / 30 / 2008$ & $06 / 30 / 2008$ & $10 / 31 / 2013$ \\
\hline Jordan & MSCI JORDAN & $04 / 30 / 2000$ & $12 / 31 / 2003$ & $04 / 30 / 2000$ & $12 / 31 / 2003$ & $10 / 31 / 2013$ \\
\hline Kuwait & MSCI KUWAIT & $12 / 31 / 2006$ & $10 / 31 / 2006$ & $10 / 31 / 2006$ & $10 / 31 / 2006$ & $10 / 31 / 2013$ \\
\hline
\end{tabular}


Panel A: L-Z countries.

\begin{tabular}{|c|c|c|c|c|c|c|}
\hline \multirow{2}{*}{ Country } & \multirow{2}{*}{ Name } & \multicolumn{4}{|c|}{ Beginning } & \multirow{2}{*}{ End } \\
\hline & & $\mathrm{EP}$ & CFP & SP & BVMV & \\
\hline Latvia & OMX RIGA OMXR & $04 / 30 / 2000$ & $09 / 30 / 2002$ & $04 / 30 / 2000$ & $09 / 30 / 2002$ & $10 / 31 / 2013$ \\
\hline Lebanon & MSCI LEBANON & $04 / 30 / 2000$ & $08 / 31 / 2003$ & $04 / 30 / 2000$ & $08 / 31 / 2003$ & $10 / 31 / 2013$ \\
\hline Lithuania & MSCI Lithuania & $05 / 31 / 2006$ & $05 / 31 / 2006$ & $05 / 31 / 2006$ & $05 / 31 / 2006$ & $10 / 31 / 2013$ \\
\hline Luxemburg & LUXEMBOURG LuxX INDEX & $05 / 31 / 2006$ & $05 / 31 / 2006$ & $05 / 31 / 2006$ & $05 / 31 / 2006$ & $10 / 31 / 2013$ \\
\hline Malaysia & MSCI MALAYSIA & $05 / 31 / 2006$ & $11 / 30 / 2006$ & $05 / 31 / 2006$ & $11 / 30 / 2006$ & $10 / 31 / 2013$ \\
\hline Mexico & MSCI MEXICO & $05 / 31 / 2006$ & $05 / 31 / 2006$ & $05 / 31 / 2006$ & $05 / 31 / 2006$ & $10 / 31 / 2013$ \\
\hline Morocco & MSCI MOROCCO & $05 / 31 / 2006$ & $08 / 31 / 2005$ & $05 / 31 / 2006$ & $08 / 31 / 2005$ & $10 / 31 / 2013$ \\
\hline Netherlands & MSCI NETHERLANDS & $05 / 31 / 2006$ & $05 / 31 / 2006$ & $05 / 31 / 2006$ & $05 / 31 / 2006$ & $10 / 31 / 2013$ \\
\hline New Zealand & MSCI NEW ZEALAND & $05 / 31 / 2008$ & $05 / 31 / 2008$ & $05 / 31 / 2008$ & $05 / 31 / 2008$ & $10 / 31 / 2013$ \\
\hline Norway & MSCI NORWAY & $04 / 30 / 2000$ & $08 / 31 / 2008$ & $04 / 30 / 2000$ & $08 / 31 / 2008$ & $10 / 31 / 2013$ \\
\hline Oman & MSCI OMAN & $04 / 30 / 2000$ & $09 / 30 / 2006$ & $04 / 30 / 2000$ & $09 / 30 / 2006$ & $10 / 31 / 2013$ \\
\hline Pakistan & MSCI PAKISTAN & $04 / 30 / 2000$ & $04 / 30 / 2000$ & $04 / 30 / 2000$ & $04 / 30 / 2000$ & $10 / 31 / 2013$ \\
\hline Peru & MSCI PERU & $04 / 30 / 2000$ & $04 / 30 / 2000$ & $04 / 30 / 2000$ & $04 / 30 / 2000$ & $10 / 31 / 2013$ \\
\hline Philippines & MSCI PHILIPPINES & $04 / 30 / 2000$ & $04 / 30 / 2000$ & $04 / 30 / 2000$ & $04 / 30 / 2000$ & $10 / 31 / 2013$ \\
\hline Poland & MSCI POLAND & $04 / 30 / 2000$ & $04 / 30 / 2000$ & $04 / 30 / 2000$ & $12 / 31 / 2000$ & $10 / 31 / 2013$ \\
\hline Portugal & MSCI PORTUGAL & $04 / 30 / 2000$ & $07 / 31 / 2003$ & $04 / 30 / 2000$ & $07 / 31 / 2003$ & $10 / 31 / 2013$ \\
\hline Qatar & MSCI QATAR & $04 / 30 / 2000$ & $04 / 30 / 2000$ & $04 / 30 / 2000$ & $04 / 30 / 2000$ & $10 / 31 / 2013$ \\
\hline Romania & MSCI Romania & $08 / 31 / 2002$ & $04 / 30 / 2001$ & $04 / 30 / 2001$ & $04 / 30 / 2001$ & $10 / 31 / 2013$ \\
\hline Russia & MSCI RUSSIA & $04 / 30 / 2000$ & $12 / 31 / 2002$ & $04 / 30 / 2000$ & $12 / 31 / 2002$ & $10 / 31 / 2013$ \\
\hline Saudi Arabia & MSCI SAUDI ARABIA & $04 / 30 / 2000$ & $03 / 31 / 2003$ & $04 / 30 / 2000$ & $03 / 31 / 2003$ & $10 / 31 / 2013$ \\
\hline Singap ore & Straits Times Index STI & $04 / 30 / 2000$ & $04 / 30 / 2000$ & $04 / 30 / 2000$ & $04 / 30 / 2000$ & $10 / 31 / 2013$ \\
\hline Slovenia & MSCI Slovenia & $04 / 30 / 2000$ & $03 / 31 / 2005$ & $04 / 30 / 2000$ & $03 / 31 / 2005$ & $10 / 31 / 2013$ \\
\hline South Africa & MSCI SOUTH AFRICA & $04 / 30 / 2000$ & $04 / 30 / 2000$ & $04 / 30 / 2000$ & $04 / 30 / 2000$ & $10 / 31 / 2013$ \\
\hline South Korea & MSCI KOREA & $04 / 30 / 2000$ & $04 / 30 / 2000$ & $04 / 30 / 2000$ & $04 / 30 / 2000$ & $10 / 31 / 2013$ \\
\hline Spain & MSCI SPAIN & $04 / 30 / 2000$ & $08 / 31 / 2001$ & $04 / 30 / 2000$ & $08 / 31 / 2001$ & $10 / 31 / 2013$ \\
\hline Sweden & MSCI SWEDEN & $04 / 30 / 2000$ & $10 / 31 / 2005$ & $04 / 30 / 2000$ & $10 / 31 / 2005$ & $10 / 31 / 2013$ \\
\hline Switzerland & MSCI SWITZERLAND & $04 / 30 / 2000$ & $04 / 30 / 2000$ & $04 / 30 / 2000$ & $04 / 30 / 2000$ & $10 / 31 / 2013$ \\
\hline Taiwan & MSCI TAIWAN & $04 / 30 / 2000$ & $04 / 30 / 2000$ & $04 / 30 / 2000$ & $04 / 30 / 2000$ & $10 / 31 / 2013$ \\
\hline Thailand & MSCI THAILAND & $04 / 30 / 2000$ & $04 / 30 / 2000$ & $04 / 30 / 2000$ & $04 / 30 / 2000$ & $10 / 31 / 2013$ \\
\hline Turkey & MSCI TURKEY & $04 / 30 / 2000$ & $04 / 30 / 2000$ & $04 / 30 / 2000$ & $04 / 30 / 2000$ & $10 / 31 / 2013$ \\
\hline Ukraine & MSCI Ukraine & $12 / 31 / 2007$ & $12 / 31 / 2007$ & $12 / 31 / 2007$ & $12 / 31 / 2007$ & $10 / 31 / 2013$ \\
\hline Un. Arab Emirates & MSCI UN. ARAB EMIRATES & $04 / 30 / 2000$ & $12 / 31 / 2001$ & $04 / 30 / 2000$ & $12 / 31 / 2001$ & $10 / 31 / 2013$ \\
\hline USA & MSCI USA & $04 / 30 / 2000$ & $12 / 31 / 2001$ & $04 / 30 / 2000$ & $12 / 31 / 2001$ & $10 / 31 / 2013$ \\
\hline Venezuela & VENEZUELA STOCK MKT & $04 / 30 / 2000$ & $12 / 31 / 2000$ & $04 / 30 / 2000$ & $12 / 31 / 2001$ & $10 / 31 / 2013$ \\
\hline Vietnam & MSCI Vietnam & $06 / 30 / 2008$ & $10 / 31 / 2007$ & $06 / 30 / 2008$ & $10 / 31 / 2007$ & $10 / 31 / 2013$ \\
\hline
\end{tabular}




\section{Appendix 4. Local country indices.}

The appendix 4. exhibits local indices representing 66 country portfolios used in the research. The timespan refers to the period during which data on all necessary returns and fundamental factor are available, which implies that I sometimes use older data (for example price data for momentum computation). The panel A presents countries with names beginning with A-K and the panel B with names beginning with L-Z.

Panel A: A-K countries.

\begin{tabular}{|c|c|c|c|c|c|c|}
\hline \multirow{2}{*}{ Country } & \multirow{2}{*}{ Name } & \multicolumn{4}{|c|}{ Beginning } & \multirow{2}{*}{ End } \\
\hline & & EP & CFP & SP & BVMV & \\
\hline Argentina & ARGENTINA MERVAL INDEX & $12 / 31 / 2000$ & $04 / 30 / 2000$ & $04 / 30 / 2000$ & $04 / 30 / 2000$ & $10 / 31 / 2013$ \\
\hline Australia & S\&P/ASX 200 INDEX & $06 / 30 / 2001$ & $04 / 30 / 2000$ & $04 / 30 / 2000$ & $04 / 30 / 2000$ & $10 / 31 / 2013$ \\
\hline Austria & AUSTRIAN TRADED ATX INDX & $05 / 31 / 2001$ & $04 / 30 / 2000$ & $04 / 30 / 2000$ & $04 / 30 / 2000$ & $10 / 31 / 2013$ \\
\hline Bahrain & BB ALL SHARE INDEX & $01 / 31 / 2001$ & $04 / 30 / 2000$ & $04 / 30 / 2000$ & $04 / 30 / 2000$ & $10 / 31 / 2013$ \\
\hline Belgium & BEL 20 INDEX & $12 / 31 / 2001$ & $04 / 30 / 2000$ & $04 / 30 / 2000$ & $04 / 30 / 2000$ & $10 / 31 / 2013$ \\
\hline Brazil & BRAZIL IBOVESPA INDEX & $06 / 30 / 2003$ & $04 / 30 / 2000$ & $06 / 30 / 2003$ & $04 / 30 / 2000$ & $10 / 31 / 2013$ \\
\hline Bulgaria & SOFIX INDEX & $12 / 31 / 2001$ & $04 / 30 / 2000$ & $04 / 30 / 2000$ & $04 / 30 / 2000$ & $10 / 31 / 2013$ \\
\hline Canada & S\&P/TSX COMPOSITE INDEX & $12 / 31 / 2000$ & $04 / 30 / 2000$ & $04 / 30 / 2000$ & $04 / 30 / 2000$ & $10 / 31 / 2013$ \\
\hline Chile & CHILE STOCK MKT SELECT & $03 / 31 / 2008$ & $03 / 31 / 2008$ & $03 / 31 / 2008$ & $03 / 31 / 2008$ & $10 / 31 / 2013$ \\
\hline China & CSI 300 INDEX & $12 / 31 / 2001$ & $04 / 30 / 2000$ & $04 / 30 / 2000$ & $04 / 30 / 2000$ & $10 / 31 / 2013$ \\
\hline Colombia & IGBC GENERAL INDEX & $12 / 31 / 2000$ & $04 / 30 / 2000$ & $04 / 30 / 2000$ & $04 / 30 / 2000$ & $10 / 31 / 2013$ \\
\hline Cyprus & GENERAL M ARKET INDEX CSE & $12 / 31 / 2001$ & $04 / 30 / 2000$ & $04 / 30 / 2000$ & $04 / 30 / 2000$ & $10 / 31 / 2013$ \\
\hline Czech Republic & PRAGUE STOCK EXCH INDEX & $12 / 31 / 2001$ & $04 / 30 / 2000$ & $04 / 30 / 2000$ & $04 / 30 / 2000$ & $10 / 31 / 2013$ \\
\hline Denmark & OMX COPENHAGEN INDEX & $04 / 30 / 2001$ & $04 / 30 / 2000$ & $04 / 30 / 2000$ & $04 / 30 / 2000$ & $10 / 31 / 2013$ \\
\hline Egypt & EGX 30 Index & $03 / 31 / 2006$ & $04 / 30 / 2000$ & $04 / 30 / 2000$ & $04 / 30 / 2000$ & $10 / 31 / 2013$ \\
\hline Estonia & OMX TALLINN OMXT & $12 / 31 / 2000$ & $04 / 30 / 2000$ & $04 / 30 / 2000$ & $04 / 30 / 2000$ & $10 / 31 / 2013$ \\
\hline Finland & OMX HELSINKI INDEX & $12 / 31 / 2000$ & $04 / 30 / 2000$ & $04 / 30 / 2000$ & $04 / 30 / 2000$ & $10 / 31 / 2013$ \\
\hline France & CAC 40 INDEX & $12 / 31 / 2005$ & $04 / 30 / 2000$ & $04 / 30 / 2000$ & $04 / 30 / 2000$ & $10 / 31 / 2013$ \\
\hline Germany & DAX INDEX & $12 / 31 / 2001$ & $04 / 30 / 2000$ & $04 / 30 / 2000$ & $04 / 30 / 2000$ & $10 / 31 / 2013$ \\
\hline Great Britain & FTSE 100 INDEX & $02 / 28 / 2006$ & $04 / 30 / 2000$ & $04 / 30 / 2000$ & $04 / 30 / 2000$ & $10 / 31 / 2013$ \\
\hline Greece & Athex Composite Share Pr & $06 / 30 / 2003$ & $04 / 30 / 2000$ & $06 / 30 / 2003$ & $04 / 30 / 2000$ & $10 / 31 / 2013$ \\
\hline Hong Kong & HANG SENG INDEX & $12 / 31 / 2001$ & $04 / 30 / 2000$ & $04 / 30 / 2000$ & $04 / 30 / 2000$ & $10 / 31 / 2013$ \\
\hline Hun & BUDAPEST STOCK EXCH INDX & $06 / 30 / 2008$ & $06 / 30 / 2008$ & $06 / 30 / 2008$ & $06 / 30 / 2008$ & $10 / 31 / 2013$ \\
\hline Iceland & OMX Iceland Small Cap Ix & $06 / 30 / 2008$ & $06 / 30 / 2008$ & $06 / 30 / 2008$ & $06 / 30 / 2008$ & $10 / 31 / 2013$ \\
\hline India & S\&P BSE SENSEX INDEX & 06/30/2008 & $06 / 30 / 2008$ & $06 / 30 / 2008$ & $06 / 30 / 2008$ & $10 / 31 / 2013$ \\
\hline Indonesia & JAKARTA COMPOSITE INDEX & $06 / 30 / 2008$ & $06 / 30 / 2008$ & $06 / 30 / 2008$ & $06 / 30 / 2008$ & $10 / 31 / 2013$ \\
\hline Ireland & IRISH OVERALL INDEX & $06 / 30 / 2005$ & $06 / 30 / 2005$ & $06 / 30 / 2005$ & $06 / 30 / 2005$ & $10 / 31 / 2013$ \\
\hline Italy & FTSE MIB INDEX & $06 / 30 / 2009$ & $06 / 30 / 2009$ & $06 / 30 / 2009$ & $06 / 30 / 2009$ & $10 / 31 / 2013$ \\
\hline Jap an & NIKKEI 225 & $06 / 30 / 2008$ & $06 / 30 / 2008$ & $06 / 30 / 2008$ & $06 / 30 / 2008$ & $10 / 31 / 2013$ \\
\hline Jordan & AMMAN SE GENERAL INDEX & $12 / 31 / 2003$ & $04 / 30 / 2000$ & $04 / 30 / 2000$ & $04 / 30 / 2000$ & $10 / 31 / 2013$ \\
\hline Kuwait & KUWAIT SE PRICE INDEX & $12 / 31 / 2006$ & $10 / 31 / 2006$ & $10 / 31 / 2006$ & $10 / 31 / 2006$ & $10 / 31 / 2013$ \\
\hline
\end{tabular}


Panel A: L-Z countries.

\begin{tabular}{|c|c|c|c|c|c|c|}
\hline \multirow{2}{*}{ Country } & \multirow{2}{*}{ Name } & \multicolumn{4}{|c|}{ Beginning } & \multirow{2}{*}{ End } \\
\hline & & EP & CFP & SP & BVMV & \\
\hline Lat via & OM X RIGA OMXR & $09 / 30 / 2002$ & $04 / 30 / 2000$ & $04 / 30 / 2000$ & $04 / 30 / 2000$ & $10 / 31 / 2013$ \\
\hline Lebanon & BLOM STOCK INDEX & $12 / 31 / 2003$ & $04 / 30 / 2000$ & $04 / 30 / 2000$ & $04 / 30 / 2000$ & $10 / 31 / 2013$ \\
\hline Lithuania & OMX VILNIUS OMXV & $05 / 31 / 2006$ & $05 / 31 / 2006$ & $05 / 31 / 2006$ & $05 / 31 / 2006$ & $10 / 31 / 2013$ \\
\hline Luxemburg & LUXEMBOURG LuxX INDEX & $05 / 31 / 2006$ & $05 / 31 / 2006$ & $05 / 31 / 2006$ & $05 / 31 / 2006$ & $10 / 31 / 2013$ \\
\hline Malaysia & FTSE Bursa Malaysia KLCI & $12 / 31 / 2006$ & $05 / 31 / 2006$ & $11 / 30 / 2006$ & $05 / 31 / 2006$ & $10 / 31 / 2013$ \\
\hline Mexico & MEXICO IPC INDEX & $05 / 31 / 2006$ & $05 / 31 / 2006$ & $05 / 31 / 2006$ & $05 / 31 / 2006$ & $10 / 31 / 2013$ \\
\hline Morocco & MADEX Free Float Index & $08 / 31 / 2005$ & $05 / 31 / 2006$ & $06 / 30 / 2005$ & $05 / 31 / 2006$ & $10 / 31 / 2013$ \\
\hline Netherlands & AEX-Index & $05 / 31 / 2006$ & $05 / 31 / 2006$ & $05 / 31 / 2006$ & $05 / 31 / 2006$ & $10 / 31 / 2013$ \\
\hline New Zealand & NZX ALL INDEX & $05 / 31 / 2008$ & $05 / 31 / 2008$ & $05 / 31 / 2008$ & $05 / 31 / 2008$ & $10 / 31 / 2013$ \\
\hline Norway & OBX PRICE INDEX & $08 / 31 / 2008$ & $04 / 30 / 2000$ & $08 / 31 / 2008$ & $04 / 30 / 2000$ & $10 / 31 / 2013$ \\
\hline Oman & MSM30 Index & $09 / 30 / 2006$ & $04 / 30 / 2000$ & $09 / 30 / 2006$ & $04 / 30 / 2000$ & $10 / 31 / 2013$ \\
\hline Pakistan & KARACHI 100 INDEX & $12 / 31 / 2000$ & $04 / 30 / 2000$ & $04 / 30 / 2000$ & $04 / 30 / 2000$ & $10 / 31 / 2013$ \\
\hline Peru & PERU LIMA GENERAL INDEX & $03 / 31 / 2001$ & $04 / 30 / 2000$ & $04 / 30 / 2000$ & $04 / 30 / 2000$ & $10 / 31 / 2013$ \\
\hline Philippines & PSEi - PHILIPPINE SE IDX & $12 / 31 / 2001$ & $04 / 30 / 2000$ & $04 / 30 / 2000$ & $04 / 30 / 2000$ & $10 / 31 / 2013$ \\
\hline Poland & WIG 20 & $12 / 31 / 2000$ & $04 / 30 / 2000$ & $04 / 30 / 2000$ & $04 / 30 / 2000$ & $10 / 31 / 2013$ \\
\hline Portugal & PSI 20 INDEX & $07 / 31 / 2003$ & $04 / 30 / 2000$ & $07 / 31 / 2003$ & $04 / 30 / 2000$ & $10 / 31 / 2013$ \\
\hline Qatar & QE Index & $11 / 30 / 2006$ & $04 / 30 / 2000$ & $04 / 30 / 2000$ & $04 / 30 / 2000$ & $10 / 31 / 2013$ \\
\hline Romania & BUCHAREST BET INDEX & $08 / 31 / 2002$ & $04 / 30 / 2001$ & $04 / 30 / 2001$ & $04 / 30 / 2001$ & $10 / 31 / 2013$ \\
\hline Russia & MICEX INDEX & $12 / 31 / 2002$ & $04 / 30 / 2000$ & $12 / 31 / 2002$ & $04 / 30 / 2000$ & $10 / 31 / 2013$ \\
\hline Saudi Arabia & TADAWUL ALL SHARE INDEX & $03 / 31 / 2003$ & $04 / 30 / 2000$ & $06 / 30 / 2002$ & $04 / 30 / 2000$ & $10 / 31 / 2013$ \\
\hline Singap ore & Straits Times Index STI & $10 / 31 / 2001$ & $04 / 30 / 2000$ & $04 / 30 / 2000$ & $04 / 30 / 2000$ & $10 / 31 / 2013$ \\
\hline Slovenia & Slovenian Blue Chip Idx & $03 / 31 / 2005$ & $04 / 30 / 2000$ & $04 / 30 / 2000$ & $04 / 30 / 2000$ & $10 / 31 / 2013$ \\
\hline South Africa & FT SE/JSE AFRICA ALL SHR & $12 / 31 / 2000$ & $04 / 30 / 2000$ & $04 / 30 / 2000$ & $04 / 30 / 2000$ & $10 / 31 / 2013$ \\
\hline South Korea & KOSPI INDEX & $12 / 31 / 2000$ & $04 / 30 / 2000$ & $04 / 30 / 2000$ & $04 / 30 / 2000$ & $10 / 31 / 2013$ \\
\hline Spain & IBEX 35 INDEX & $12 / 31 / 2001$ & $04 / 30 / 2000$ & $08 / 31 / 2001$ & $04 / 30 / 2000$ & $10 / 31 / 2013$ \\
\hline Sweden & OM X STOCKHOLM 30 INDEX & $10 / 31 / 2005$ & $04 / 30 / 2000$ & $04 / 30 / 2000$ & $04 / 30 / 2000$ & $10 / 31 / 2013$ \\
\hline Switzerland & SWISS M ARKET INDEX & $12 / 31 / 2000$ & $04 / 30 / 2000$ & $04 / 30 / 2000$ & $04 / 30 / 2000$ & $10 / 31 / 2013$ \\
\hline Taiwan & TAIWAN TAIEX INDEX & $12 / 31 / 2000$ & $04 / 30 / 2000$ & $04 / 30 / 2000$ & $04 / 30 / 2000$ & $10 / 31 / 2013$ \\
\hline Thailand & STOCK EXCH OF THAI INDEX & $12 / 31 / 2001$ & $04 / 30 / 2000$ & $04 / 30 / 2000$ & $04 / 30 / 2000$ & $10 / 31 / 2013$ \\
\hline Turkey & BIST NATIONAL 100 INDEX & $12 / 31 / 2000$ & $04 / 30 / 2000$ & $04 / 30 / 2000$ & $04 / 30 / 2000$ & $10 / 31 / 2013$ \\
\hline Ukraine & PFTS Index & $12 / 31 / 2007$ & $12 / 31 / 2007$ & $12 / 31 / 2007$ & $12 / 31 / 2007$ & $10 / 31 / 2013$ \\
\hline Un. Arab Emirates & ADX GENERAL INDEX & $12 / 31 / 2001$ & $04 / 30 / 2000$ & $04 / 30 / 2000$ & $04 / 30 / 2000$ & $10 / 31 / 2013$ \\
\hline USA & S\&P 500 INDEX & $12 / 31 / 2001$ & $04 / 30 / 2000$ & $04 / 30 / 2000$ & $04 / 30 / 2000$ & $10 / 31 / 2013$ \\
\hline Venezuela & VENEZUELA STOCK MKT & $12 / 31 / 2001$ & $04 / 30 / 2000$ & $04 / 30 / 2000$ & $04 / 30 / 2000$ & $10 / 31 / 2013$ \\
\hline Vietnam & HO CHI MINH STOCK INDEX & $10 / 31 / 2007$ & $06 / 30 / 2008$ & $06 / 30 / 2008$ & $06 / 30 / 2008$ & $10 / 31 / 2013$ \\
\hline
\end{tabular}

